Aus der Chirurgischen Klinik für Allgemein-, Viszeral und Thoraxchirurgie ( Chefarzt Prof. Dr. med H.-F. Weiser ) des Diakoniekrankenhauses Rotenburg ( Wümme )

\title{
Anastomosenprotektion am Kolorektum durch Umhüllung mit "Small intestinal submucosa “ im Großtiermodell des Schweins
}

\author{
Inaugural-Dissertation \\ zur Erlangung des Doktorgrades \\ der Medizinischen Fakultät \\ der Georg-August-Universität zu Göttingen
}

vorgelegt von

Vladan Crnogorac

aus Berlin

Göttingen 2012 
Dekan:

I. Berichterstatter:

II. Berichterstatter/in:

III. Berichterstatter/in:

Tag der mündlichen Prüfung : 16.07.2014
Prof. Dr. med. M. P. Schön

Prof. Dr. med. H.-F. Weiser

Prof. Dr. med. Harald Schwörer

Prof. Dr. med. Margarete Schön 


\section{Inhaltsverzeichnis}

1. Einleitung 5

1.1 Einführung 5

1.2 Gastrointestinale Anastomoseninsuffizienz 5

1.2.1 Definition 5

1.2.2 Morbidität und Mortalität 5

$\begin{array}{lll}1.3 & \text { Wundheilung } & 7\end{array}$

1.3.1 Allgemeine Wundheilung 7

1.3.2 Gastrointestinale Wundheilung 8

1.3.3 Gastrointestinale Anastomosenheilung 9

1.3.4 Bedeutung der Extrazellulären Matrix in der Wundheilung 10

$\begin{array}{lll}1.3 .5 & \text { Kollagenmetabolismus } & 11\end{array}$

1.4 Beeinflussende Komponenten der gastrointestinalen $\begin{array}{ll}\text { Anastomosenheilung } & 14\end{array}$

1.4.1 Einfluss systemischer Faktoren 14

1.4.2 Einfluss lokaler Faktoren 15

1.5 Anastomosenprotektion am Gastrointestinaltrakt 16

1.6 Aktueller Stand der Wissenschaft 17

1.7 Extrazelluläre Matrices (ECM) 18

1.7.1 Small Intestinal Submucosa (SIS) 19

1.7.2 Bisherige Evidenz des Einflusses von SIS auf gastrointestinale $\begin{array}{ll}\text { Heilungsprozesse } & 21\end{array}$

2. Fragestellung 23

3. Material und Methoden 24

3.1 Tiermodell 24

3.1.1 Versuchstiere 24

3.1.2 Untersuchungsgruppen 24

3.1.3 Anästhesie und präoperatives Management 24

3.1.4 Operativer Versuchsablauf I 25

3.1.5 Anlage der Anastomose 26

3.1.6 Umhüllung der Anastomose mit SIS 26

$\begin{array}{lll}3.1 .7 & \text { Postoperativer Verlauf } & 27\end{array}$ 
$\begin{array}{lll}\text { 3.1.8 Operativer Versuchsablauf II } & 28\end{array}$

3.1.9 Entnahme des Colon descendens 28

3.2 Radiologische Untersuchung 28

3.2.1 Auswertung 29

3.3 Berstungsdruckmessung 29

3.4 Makroskopische Untersuchung 30

3.5 Histologie 31

3.5.1 Vorbereitung 31

3.5.2 Hämatoxylin-Eosin-Färbung 31

$\begin{array}{lll}3.5 .3 & \text { Auswertung } & 31\end{array}$

3.6 Statistik 32

4. Ergebnisse 32

$4.1 \quad$ Überleben 32

4.2 Klinischer Verlauf 32

4.3 Makroskopische Untersuchung 33

$\begin{array}{lll}4.4 & \text { Berstungsdruck } & 37\end{array}$

$\begin{array}{lll}4.5 & \text { Radiologische Auswertung } & 37\end{array}$

$\begin{array}{lll}4.6 & \text { Histologie } & 39\end{array}$

5. Diskussion 44

6. Zusammenfassung 49

7. Anhang 51

7.1 Abkürzungsverzeichnis 51

7.2 Literaturverzeichnis 53 


\section{Einleitung}

\subsection{Einführung}

In der Abdominalchirurgie wird die Anlage einer kolorektalen Anastomose regelmäßig als operatives Verfahren durchgeführt. Obwohl die Naht der intestinalen Anastomosen zum Grundlagenrepertoire der Viszeralchirurgie gehört, werden Anastomoseninsuffizienzen als Komplikationen abdominal-chirurgischer Interventionen immer noch am meisten gefürchtet.

Die Auswirkungen einer Anastomoseninsuffizienz sind folgenschwer. Die fäkal bakterielle Kontamination der Bauchhöhle mit Entstehung einer Peritonitis und schwerer Sepsis führt oft zu einer lebensbedrohlichen Situation des Patienten.

Historisch konzentrierte sich die chirurgische Forschung insbesondere auf die richtige Nahttechnik von Anastomosen, da in erster Linie die falschen Nahttechniken als Hauptursache der Anastomoseninsuffizienz galten (Boschung (2003)). Heute existiert ein breites Spektrum in der Anastomosenforschung, dass sich nicht alleine auf die Einflüsse der richtigen Nahttechnik beschränkt. Hierzu sind die Forschungsuntersuchungen noch nicht beendet und werden auch zukünftig von wichtiger Bedeutung sein.

\subsection{Gastrointestinale Anastomoseninsuffizienz}

\subsubsection{Definition}

Eine Darmanastomose ist eine operativ angelegte Verbindung zwischen zwei Darmenden, die zur Wiederherstellung der Darmkontinuität dient (Pschyrembel (2004)). In der Abdominalchirurgie werden Anastomosenanlagen im Rahmen von Operationen im Gastrointestinaltrakt durchgeführt. Zu den Hauptindikationen gehören u.a. Resektionen von Tumoren, lleus, gastrointestinale Perforationen oder Inkarzeration von Hernien.

Die Anastomoseninsuffizienz ist die Undichtigkeit einer Anastomose.

\subsubsection{Morbidität und Mortalität}

Anastomoseninsuffizienzen führen zu einer erhöhten postoperativen Morbidität und Mortalität (Mann et al. (1996), Pakkastie et al. (1994)). Nahezu ein Drittel der Patienten verstirbt anhand der Folgen einer Anastomoseninsuffizienz (Debas und Thomson (1972), Schrock et al. (1973)). Die Mortalitätsrate nach Ausbildung einer 
Anastomoseninsuffizienz wird in der Literatur zwischen $30 \%$ und $38 \%$ beziffert (Mann et al. (1996), Vandertoll und Beahrs (1965)).

In einer retrospektiven Studie analysierten Pakkastie et al. (1994) die Entstehung von Anastomosennsuffizienzen an 134 Patienten, an denen aufgrund von gut oder bösartigen Tumoren kolorektale Resektionen durchgeführt wurden. Die Gesamtmortalität lag bei $1 \%$ und Komplikationen entstanden bei $21 \%$. Bei $12 \%$ der Patienten kam es zu einer Anastomoseninsuffizienz, von denen $69 \%$ operativ revidiert wurden. Dabei konnte festgestellt werden, dass die Entfernung zum Analkanal einen deutlichen Einfluss auf die Entwicklung von Anastomoseninsuffizienzen hat.

Weitere Studienuntersuchungen beschreiben Insuffizienzraten von lleum und Kolon zwischen 3-51 \% (Akyol et al. (1992), Rullier et al. (1998)).

Die breiten Abweichungen innerhalb dieser Studien lassen sich unter anderem durch den Zusammenhang zur Lokalisation der Anastomose erklären. Sehr hohe Komplikationsraten besitzen Anastomosen am Ösophagus und am distalen Rektum mit $13 \%$ bis zu 51\% (Briel et al. (2004), Lorentz et al. (1989), Marjanovic et al. (2008)), während Operationen am Dünndarm vergleichbar geringe Insuffizienzraten zeigen (Hesp et al. (1986)). Als eine Erklärung dafür gelten u.a. die bessere Gefäßversorgung und kleinere Scherkräfte.

Ein weiterer möglicher Grund ist das Vorkommen der Serosa. Die extraperitoneal gelegenen Anteile des Ösophagus und des distalen Rektums besitzen keine Serosa (Abramowitz und Mc Alister (1969), Martens et al. (1992), Stelzner (1982)).

Hesp et al. (1986) schilderten in einer rückblickenden Untersuchung von 1977-1981 an insgesamt 143 Patienten die Inzidenzrate von Anastomoseninsuffizienzen am Dünndarm. Hier entwickelten sich vergleichsweise nur bei 3,4 \% der Patienten Anastomoseninsuffizienzen.

Desweiteren lässt sich feststellen, dass Anastomoseninsuffizienzen nach Notfalloperationen wesentlich öfter vorkommen als nach programmiert geplanten Eingriffen (Foster et al. (1985)). Mann et al. (1996) prüften an 320 Patienten das Auftreten von Anastomoseninsuffizienzen, die einer kolorektalen Resektion bedurften. Dabei wurde zwischen geplanten und Notfalloperationen differenziert. Die Gesamtmortalität lag bei $2,7 \%$, die Morbidität bei $18,3 \%$ und die Anastomoseninsuffizienzrate betrug $3,4 \%$. Die elektiv geplanten Eingriffe zeigten 
eine Insuffizienzrate von 0,6\%. Bei elektiven tiefen Rektumresektionen konnte eine Inzidenzrate von $7 \%$ festgestellt werden.

Die Morbidität bei Notfalleingriffen lag wesentlich höher. In Abhängigkeit der postoperativen Begleiterscheinungen lag die Morbidität bei begleitender Peritonitis bei $46 \%$, bei Obstruktionen betrug die Morbidität $26 \%$, die Mortalität $7 \%$.

Im Rahmen einer intraabdominellen Entzündung betrug die Insuffizienzrate 14,8 \% und ohne Infektion 0,8\%. Die Mortalität betrug $18 \%$.

Rullier et al. (1998) prüften Risikofaktoren für die Entstehung von Anastomoseninsuffizienzen. Im Zeitraum von 15 Jahren von 1980-1995 wurden anteriore Rektumresektionen bei Vorliegen eines Rektumkarzinoms durchgeführt. In $12 \%$ der Fälle entwickelten sich Insuffizienzen. Das Ergebnis dieser Studie konnte lediglich das männliche Geschlecht sowie die Entfernung der Anastomose zur Linea anorectalis von kleiner als $5 \mathrm{~cm}$ als einzige Risikofaktoren feststellen.

In einer aktuellen systematischen Übersichtsarbeit von Neutzling et al. (2012) konnte keine Überlegenheit der gestapelten über die handgenähte Anastomosennahttechnik in der kolorektalen Chirurgie demonstriert werden.

Die erhöhten ökonomischen Kosten für den verlängerten Krankenhausaufenthalt als Folge von Anastomoseninsuffizienzen, Funktionsstörungen der häufig stenotisch ausheilenden insuffizienten Anastomosen, sowie das erhöhte Risiko für lokale Karzinomrezidive in der onkologischen Chirurgie stellen wesentliche wirtschaftliche und medizinische Folgen dar (Makela et al. (2003), Nesbakken et al. (2001), Petersen et al. (1998)).

\subsection{Wundheilung}

Das Verständnis der Wundheilungsabläufe und deren einzelnen Phasen bei der Entwicklung von Anastomoseninsuffizienzen ist entscheidend. Der Vorgang des Wundheilungsablaufs ist komplex, da eine große Zahl von Zellen und Zytokinen beteiligt ist. Das Verständnis ihrer Einzelkomponenten ist jedoch unverzichtbar zur Beurteilung der Biokompatibilität von Fremdmaterialien. Insbesondere in Bezug auf die Anwendung von extrazellulären Matrices können Schnittstellen gefunden werden und Erklärungsversuche unternommen werden. 


\subsubsection{Allgemeine Wundheilung}

Die Wundheilung kann als Defektverschluss durch Vernarbung in Verbindung mit Epithelialisierung definiert werden. Sie läuft bis auf Ausnahmen uniform und organunspezifisch ab.

Die Wundheilung lässt sich in drei Phasen einteilen (Tsirogianni et al. (2006)). Für die Chirurgie ist das Verständnis für diesen dreiphasigen Prozess der Wundheilung entscheidend.

Die erste Phase der Wundheilung wird gemeinhin als die entzündliche (Inflammations-Phase) verstanden. An erster Stelle der sequentiellen Abläufe steht die Blutstillung. Die einströmenden Thrombozyten bilden einen unlöslichen Fibrinklot an der verletzten Stelle. Durch die erhöhte Gewebepermeabilität kommt es zu einem hohen Zufluss inflammatorischer Zellen (Moore (1999)). Zu den ersten Zellen gehören die neutrophilen Granulozyten, die nekrotisches Gewebe von der Wunde entfernen und die Wunde von Krankheitserregern reinigen. Danach wandern Makrophagen in das Gewebe und bilden die dominante Zellart. Ihnen kommt in dieser Phase der Wundheilung eine Schlüsselstelle zu, da sie eine Reihe von Tissue-Growth-Factors bilden (Aderem (2003)).

Die zweite sogenannte Proliferationsphase ist durch die Migration der Fibroblasten in die Wunde charakterisiert. Ab dem vierten Tag werden die Fibroblasten zur dominierenden Zellreihe. Der Fibroblasteneinstrom wird durch Platelet-derivedgrowth-factor, Transforming Growth factor- $\beta$ und basic-Fibroblast-Growth-factor vermittelt. Die Fibroblasten beginnen mit der Kollagensynthese und bilden kollagenreiches Granulationsgewebe und ersetzen damit die vorherrschende Matrix. Innerhalb dieser Zeit setzt auch die Angiogenese zur Sicherstellung der Sauerstoffversorgung des Gewebes ein (Greiling und Clark (1997)).

Das Remodeling bildet die dritte und damit letzte Phase der Wundheilung. Innerhalb dieser Umbauphase nimmt die Dichte an Makrophagen und Fibroblasten ab. Die Kollagensynthese nimmt $\mathrm{zu}$ und Kollagenfasern werden $\mathrm{zu}$ Kollagenbündeln umgebaut. Im Vordergrund dieser Umbauphase stehen die kontraktilen Vorgänge, mit der Ausbildung einer Wundkontraktion durch die Bildung retraktiler Elemente. Der Anteil an Typ-III-Kollagen reduziert sich in dieser Phase auf $20 \%$ (Tomasek et al. (2002)). 


\subsubsection{Gastrointestinale Wundheilung}

Die Wundheilung im Gastrointestinaltrakt beginnt organunspezifisch analog zur oben beschriebenen Wundheilung mit der inflammatorischen Phase. Nach der Blutstillung und Vasokonstriktion kommt es zum Einstrom von neutrophilen Granulozyten und Makrophagen in die Wunde, die daraufhin mit der Bildung von Wachtumsfaktoren starten. Die Fibroblasie mit der Bildung von kollagenreichem Granulationsgewebe bestimmt den Beginn der proliferativen Wundheilungsphase. Es kommt zu einer Neubildung von Kollagen. Innerhalb der ersten 3 Tage findet eine Kollagenaseaktivität statt (Hawley et al. (1970), Hendriks et al. (1985)). Die Anastomosenstärke ist in dieser frühen Phase der Heilung schwach, so dass der Zusammenhalt der Anastomose hauptsächlich durch das verwendete Nahtmaterial gewährleistet wird (Graham et al. (1987), Martens und Hendriks (1991), Thornton und Barbul (1997)).

Die Fibroblasten spielen zusammen mit den glatten Muskelzellen eine bedeutende Rolle bei der Synthese neuer Kollagenfasern. Die Anastomosenstärke ist in den ersten zwei postoperativen Tagen noch sehr gering. Die Kollagenbildung erhöht sich ab dem dritten Tag (Martens et al. (1992)).

Die Endphase der Anastomosenheilung ist charakterisiert durch die Abnahme von neutrophilen Granulozyten und Makrophagen, sowie die Ausbildung retraktiler Fasern. Zusätzlich kommt es zum Umbau der Kollagenfasern zu Kollagenbündeln. Die größte Bedeutsamkeit für die Stabilität besitzt die Tunica submucosa. In dieser Schicht befindet sich der wichtigste Anteil an Kollagenfasern (Halsted (1887)).

\subsubsection{Gastrointestinale Anastomosenheilung}

Es sind viele lokale und systemische Risikofaktoren für die Heilung gastrointestinaler Anastomosen bekannt. Dennoch bilden die komplexen biochemischen und molekularen Mechanismen immer noch die Grundlage für Heilungsstörungen am Gastrointestinaltrakt. Wesentliche postoperative Abläufe der Anastomosenregeneration werden aber auf physiologische Veränderungen im Kollagenmetabolismus der darmwandeigenen extrazellulären Matrix zurückgeführt (Witte und Barbul (2003), Hawley et al. (1970)).

Die erste postoperative Phase nach Anlage einer gastrointestinalen Anastomose wird geprägt durch eine temporär reduzierte mechanische Belastbarkeit und einen geringen Kollagengehalt im Anastomosenbereich, mit Minimalwerten zwischen dem 
dritten und vierten postoperativen Tag. Diese lokal reduzierte Kollagenkonzentration ist auf eine lokal erhöhte Aktivität des Enzyms Kollagenase nach Anastomosenanlage zurückzuführen (Hawley et al. (1970)). Danach kommt es zur Steigerung der de-novo-Kollagensynthese. Gleichzeitig kommt es bis zum siebten postoperativen Tag zu einer raschen Normalisierung der lokalen Kollagenolyse und damit zu einem raschen Anstieg der mechanischen Anastomosenstabilität (Chowcat et al. (1990)). Daher wird in den ersten postoperativen Tagen die Sicherheit der Anastomose hauptsächlich durch den Kollagengehalt der darmeigenen ECM, welche v.a. in der Tunica submucosa lokalisiert ist, gewährleistet (Martens und Hendriks (1991)). In der klinischen Praxis entwickeln sich regenerationsbedingte Anastomoseninsuffizienzen am Kolorektum meistens zwischen dem fünften und siebten postoperativen Tag, während technisch bedingte Insuffizienzen meistens aufgrund einer primäre Undichtigkeit der Anastomose entstehen und deutlich früher auftreten.

\subsubsection{Bedeutung der Extrazellulären Matrix in der Wundheilung}

Die extrazelluläre Matrix besteht aus einem dreidimensionalen Gerüst verschiedener Kollagentypen wie Elastin, Fibronektin, Glykosaminoglykanen und Proteoglykanen. Sie enthällt alle unlöslichen Faktoren des interstitiellen Raumes und Elemente der Basalmembran. Die ECM dient hauptsächlich als Strukturbaustein und beeinflusst zudem die Zellentwicklung und Zellphysiologie.

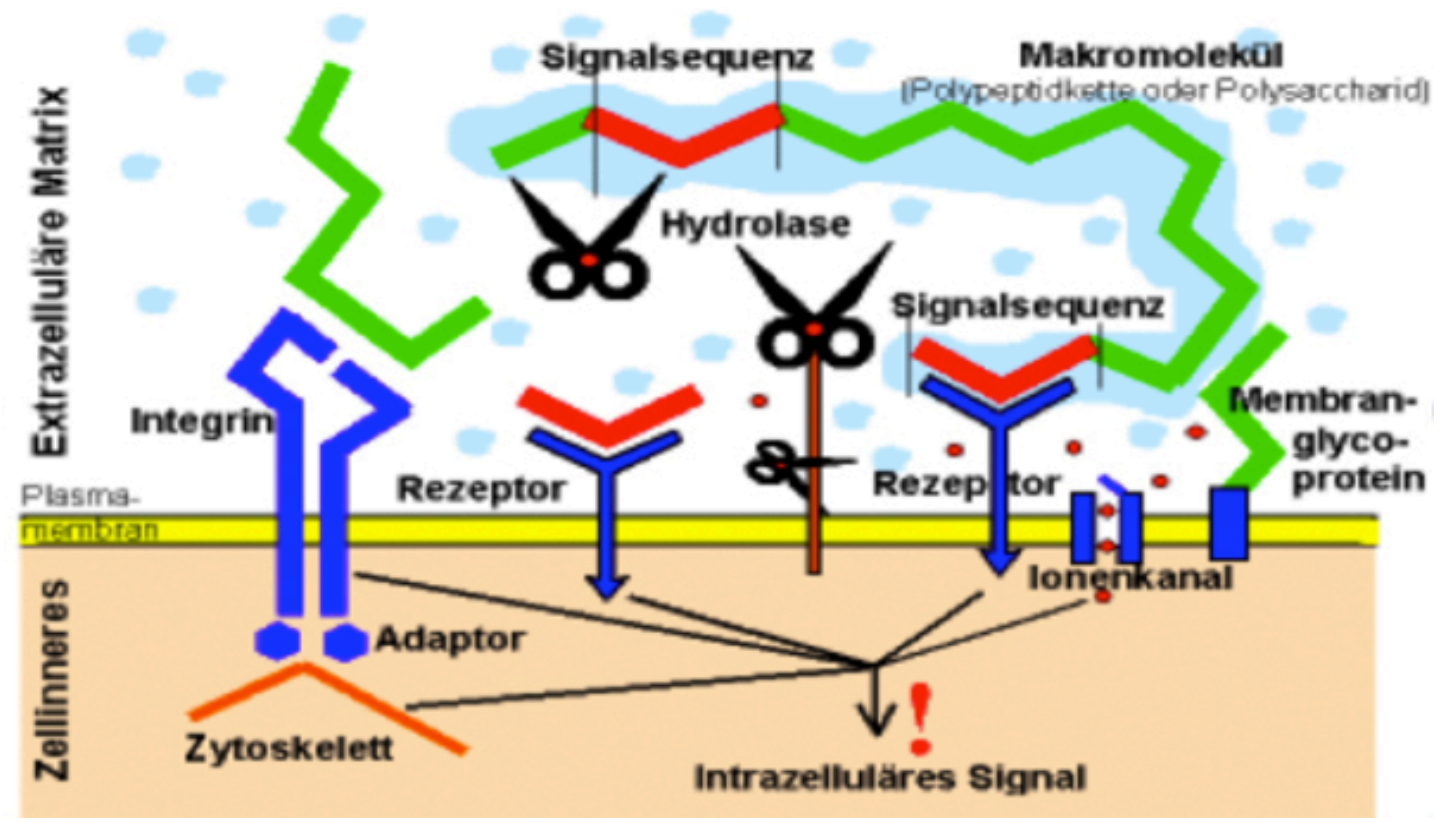

Abbildung 1: Schematische Darstellung der extrazellulären Matrix nach Franken (2010, S.4), UB (2005) 
Zu den Aufgaben der ECM gehört die Regulation zellulärer Funktionen, wie die der Zelladhäsion und der Organisation eines Transportsystems für Nährstoffe. Gomez et al. (1997) konnten Defekte der Extrazellulären Matrix mit pathologischen Prozessen, wie Entzündungen, chronisch degenerativen Erkrankungen und Tumorinvasion, in Verbindung bringen. Zusätzlich nimmt die ECM an entscheidenden Prozessen der Wundheilung teil (Rhagow (1994)). Stumpf et al. (2004) und Charrier et al. (2004) konnten in einer prospektiven Studie an Kolonkarzinom-Patienten nachweisen, dass sich Milieuveränderungen in der ECM störend auf die Anastomosenheilung auswirken. Die einzelnen Elemente der extrazellulären Matrix verändern sich parallel zu den Phasen der Wundheilung. Kurz nach einer Verletzung bildet sich eine provisorische Wundmatrix, die überwiegend aus Fibrin und Fibronektin besteht. Nach einigen Tage sind von Fibroblasten synthetisierte Kollagene und Proteoglykane die Hauptbestandteile der Matrix (Gailit und Clark (1994)). Pathologisch erhöhte Proteasenkonzentrationen verschieben das Wundmilieu in Richtung destruktiver Prozesse. Dabei werden Elemente der ECM inklusive der Wachstumsfaktoren abgebaut. Die Abbauvorgänge erfolgen hauptsächlich durch die MatrixMetalloproteinasen (MMPs). Die MMPs sind proteolytische Enzyme, die wesentlich für die Umstrukturierung der Extrazellulärmatrix im Rahmen physiologischer und pathologischer Prozesse verantwortlich sind. Sie sind ebenfalls in der Umbauphase der Wundheilung aktiv. Die TIMPs sind spezifische Inhibitoren der MMPs und kontrollieren wesentlich den Umbauprozess. Sie verhindern, dass Teile der funktionellen Matrix abgebaut werden. In chronischen Wunden kommt es durch die entzündliche Reaktion zu einer Erhöhung der Proteasenkonzentration und damit zu einer Dysbalance zwischen MMPs und TIMPs. Dies kann zu einem pathologisch gesteigerten Matrix-Abbau führen. Des Weiteren arbeitet die ECM eng mit intrazellulären Prozessen zusammen. Viele Abläufe werden über transmembranäre Rezeptoren und über die Interaktion mit Bestandteilen der ECM vermittelt und ausgelöst (Lodish et al. (2008)).

\subsubsection{Kollagenmetabolismus}

Kollagen ist ein wichtiges Element der Extrazellulären Matrix (ECM) und damit des Bindegewebes. Zu den weiteren Bestandteilen der ECM gehören Elastin, Proteoglykane und Glykoproteine. 
Die Zugfestigkeit der Anastomose entsteht hauptsächlich aus der Produktion verschiedener Stoffe der extrazellulären Matrix. Dabei nimmt die Kollagensynthese eine entscheidende Bedeutung ein, insbesondere in der frühen Phase der Anastomosenheilung.

Unmittelbar nach der Operation zeigt sich eine lokal reduzierte Kollagenkonzentration durch die einsetzende Kollagenolyse. Danach kommt es ab dem zweiten postoperativen Tag zur Steigerung der Kollagenkonzentration durch die einsetzende Kollagenneusynthese. Die Kollagenproduktion um die Anastomose steigt in dieser Phase stärker als in unoperierten Darmanteilen [Joshi (2005)]. Cronin et al. (1968) konnten dies in ihren tierexperimentellen Untersuchungen nachweisen. Der Gesamtgehalt der Kollagenkonzentration in der postoperativen Phase resultiert aus der Kollagenneusynthese und der direkt postoperativ beginnenden Kollagenolyse durch das Enzym Kollagenase.

Die mechanische Anastomosenstabilität ist zwischen dem dritten und vierten postoperativen Tag am schwächsten. Ab dem siebten postoperativen Tag kommt es zu einem schnellen Anstieg der mechanischen Anastomosenstabilität (Chowcat et al. (1990)).

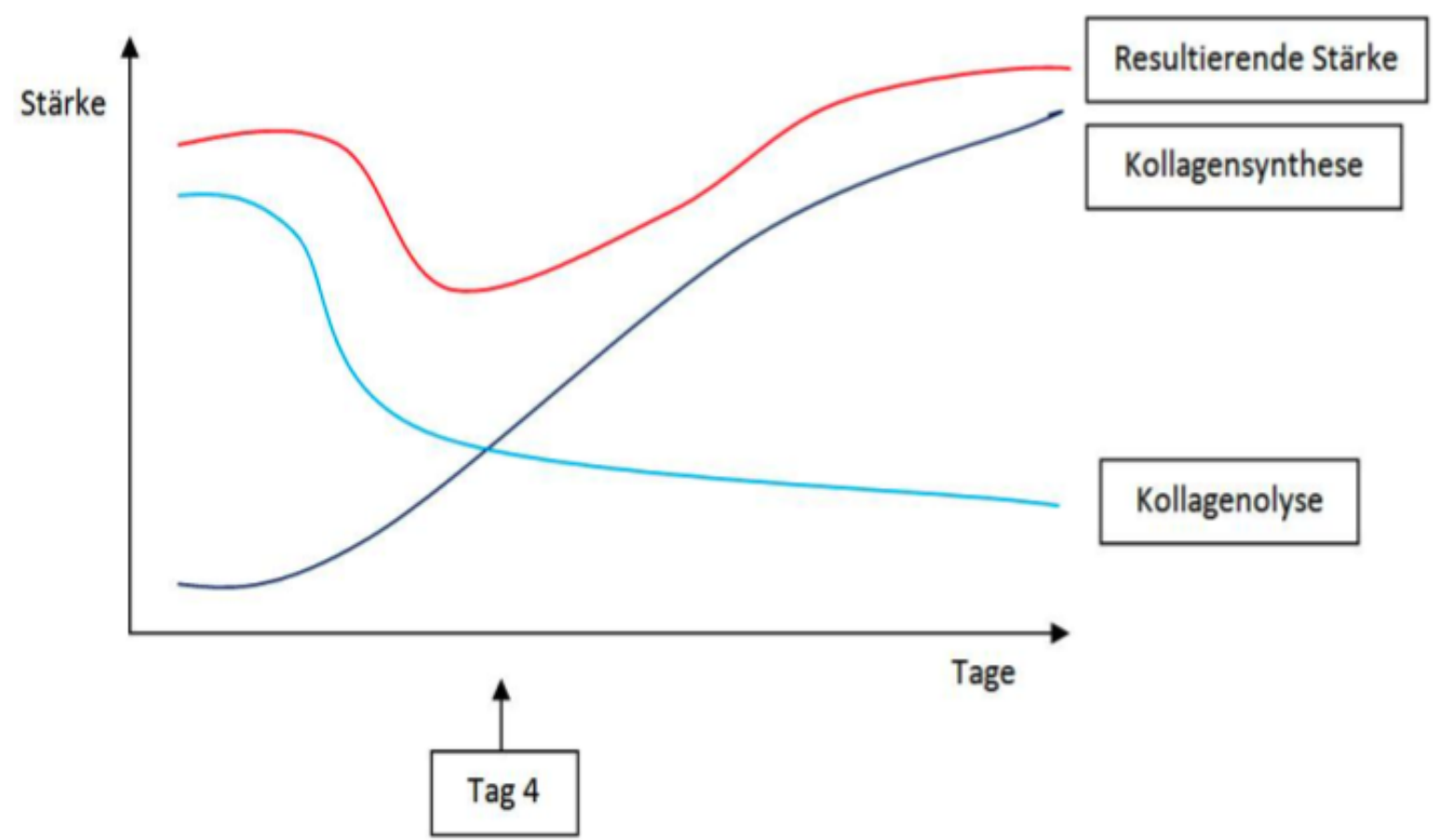

Abbildung 2. Stärke enteraler Anastomosen in Abhängigkeit vom postoperative Tag (Thompson et al. (2006) S.131-136) 
Kollagen Typ I und III kommt sowohl in der Haut als auch im GIT vor. Im GIT existiert auch das Kollagen Typ V (Typ I: 68 \%, Typ III: 20 \% und Typ V: 12 \%) (Thornton und Barbul (1997)). Unter den bekannten Kollagen-Varianten ist insbesondere das zugfeste Kollagen Typ I für die mechanische Gewebebelastbarkeit verantwortlich, während das mechanisch instabilere Kollagen Typ III vornehmlich während der frühen Wundheilungsphase exprimiert und anschließend im Rahmen der Organisation durch Kollagen Typ I ersetzt wird.

Bei der Kollagenbildung sind als Kofaktoren Eisen, Kupfer und Vitamin $C$ erforderlich (Irvin (1978), Ringsdorf und Cheraskin (1982)). Nicht nur die Kollagensynthese, sondern auch der Abbau gehört zum physiologischem Bindegewebsumbau. Verantwortlich für den Abbau des Kollagens sind insbesondere die Matrixmetalloproteinasen-1 (Kollagenase-1), $\quad-8 \quad$ (Kollagenase-2) und $\quad-13$ (Kollagenase-3). Eine Entzündung bewirkt über Makrophagen eine Aktivierung der Kollagenase mit nachfolgend vermehrtem Kollagen-Abbau. Mastboom fand 1991 heraus, dass sich der postoperative Kollagenabfall durch Gabe von NSAID (nichtsteroidale antiinflammatorische Drugs) über eine Inaktivierung der Kollagenase vermindern ließ. Allerdings kam es zu einer erheblichen Steigerung der Anastomoseninsuffizienzen und letalen Verläufe (Mastboom (1991)).

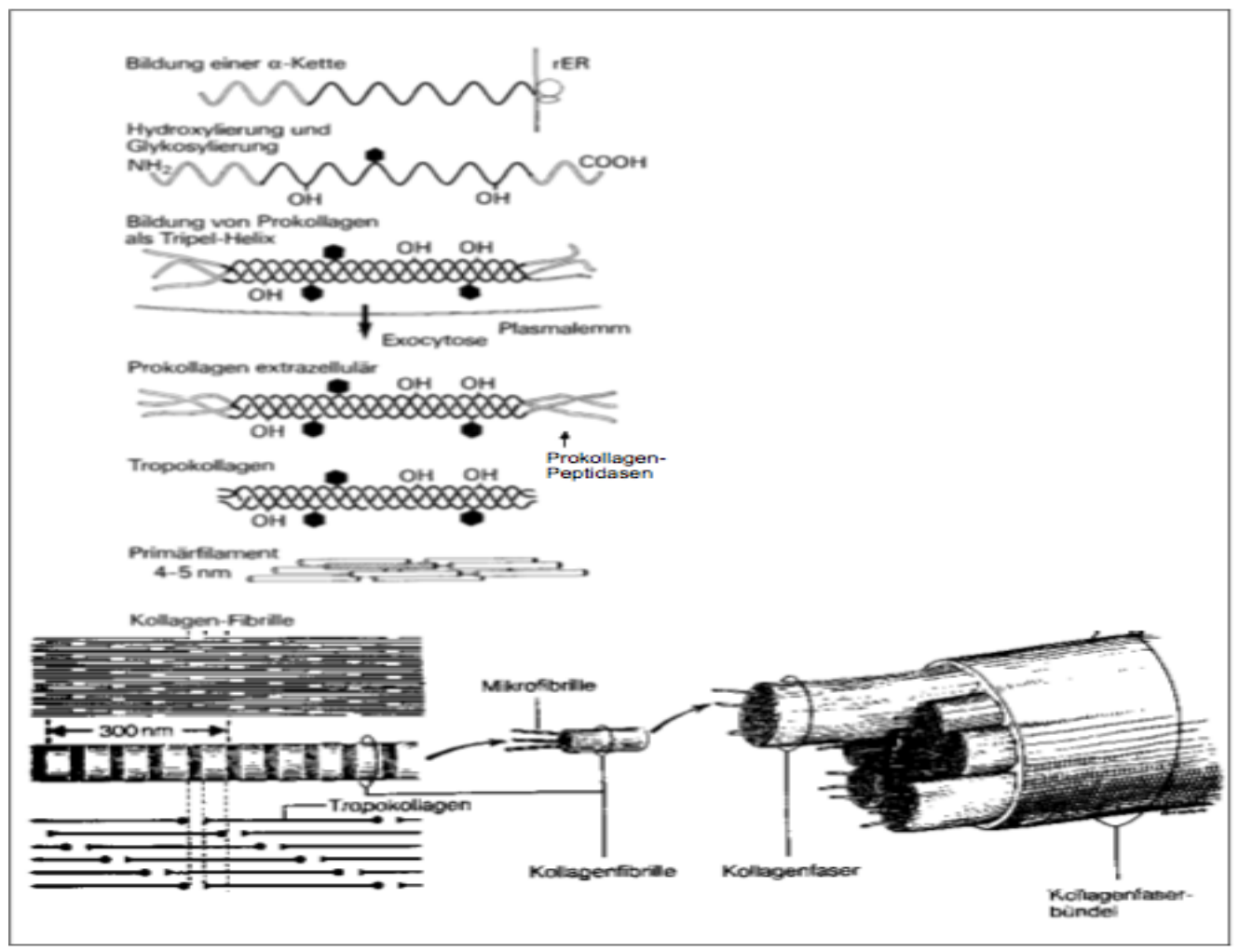

Abbildung 3. Aufbau von Kollagenfasern und Kollagenfibrillen (Junqueira und Carneiro (1991) S.153, Bucher und Wartenberg (1989) S.155). 


\subsection{Beeinflussende Komponenten der gastrointestinalen Anastomosenheilung}

In der Vergangenheit konnten viele unterschiedliche lokale und systemische Faktoren beschrieben werden, die entweder eine günstige oder beeinträchtigende Wirkung auf die Heilung von gastrointestinalen Anastomosen haben.

In dieser Arbeit sollen hier die Wichtigsten beschrieben und eine mögliche Schnittstelle zur Anwendung von extrazellulären Matrices gefunden werden.

\subsubsection{Einfluss systemischer Faktoren}

Eine weitere wichtige Einflussgröße für die Entstehung von Anastomoseninsuffizienzen stellen vor allem systemische Faktoren des Patienten dar. Lobo et al. (2002) und (2006) beschreiben den Zusammenhang zwischen hohem intraabdominellem Druck (IAD) und einer möglichen Ödembildung in Bauchorganen.

Die Entwicklung eines intestinalen Ödems führt aus unterschiedlichen Gründen zu einer Störung der Anastomosenheilung. Insbesondere an der Nahtstelle der Anastomose sind erhöhte Scher- und Zugkräfte festzustellen. Der erhöhte IAD führt zu einer kompromittierenden Versorgung im kapillären Strombett. Es kommt zu einer Verringerung der Sauerstoffspannung im Gewebe. Die verminderte Gewebeperfusion führt zu einer Reduktion des Kollagengehalts und das Risiko der Entstehung einer Anastomoseninsuffizienz steigt.

Hartmann et al. (1992) schilderten in einer tierexperimentellen Untersuchung an Ratten die negative Wirkung von Dehydration auf die Anastomosenheilung.

Intraoperativer Blutverlust mit daraus resultierender Substitution von Blutprodukten führt zu einer höheren Insuffizienzrate. Dabei steigt auch das Risiko einer intraabdominellen Infektion und Sepsis (Soeters et al. (2002), Tadros et al. (1992)).

Foster et al. (1985) konnten in einer tierexperimentellen Studie an Kanninchen nachweisen, dass Blutverluste während einer Operation zu einer deutlichen Minderung des Kollagengehalts führen. Der Blutverlust führte zu einer verringerten Gewebeperfusion mit einer resultierenden verminderten Sauerstoffspannung im Gewebe, so dass im Falle eines hypovolämischen Schocks die Perfusion im GI-Trakt herunter gefahren wird (Thompson et al. (2006), Mast (1997), Thornton und Barbul (1997), Martens et al. (1992)).

In weiteren unterschiedlichen experimentellen und klinischen Studien konnten auch vor allem postradiogene Zustände und Cortisonmedikation als wesentliche negative 
Prognosefaktoren für die Entwicklung von Anastomoseninsuffizienzen festgestellt werden (Polat et al. (2002), Seifert et al. (1995), Jahnson et al. (1998)). Corticosteroide z.B. führen über die Hemmung von Kollagensynthese und Fibroblastenproliferation zu einer eingeschränkten Neubildung von extrazellulärer Matrix und von Granulationsgewebe im Anastomosenbereich (Phillips et al. (1992)). Desweiteren gelten Diabetes mellitus, Hypoproteinämie, Nikotinkonsum, Alkoholkonsum, Adipositas und die intraoperative Transfusion von Blutprodukten als wesentliche Risikofaktoren für die Entstehung von Anastomoseninsuffizienzen (Buchs et al. (2007), Choi et al. (2006), Sørensen et al. (1999), Nickelsen et al. (2005), Matthiessen et al. (2004), Konishi et al. (2006).

Stumpf et al. (2002) konnten in postoperativen Untersuchungen nachweisen, dass bei Patienten mit Ausbildung einer Anastomoseninsuffizienz ein deutlich geringerer Kollagengehalt vorlag im Vergleich zu denen, die keine Anastomoseninsuffizienz entwickelt haben. Damit konnte er eine Verbindung zwischen erniedrigtem Kollagengehalt im anastomosentragenden Kolon und einer erhöhten Rate von Anastomoseninsuffizienzen herstellen.

Martens und Hendriks (1991) zeigten, dass in den ersten postoperativen Tagen die Sicherheit der Anastomose hauptsächlich durch den Kollagengehalt der darmeigenen ECM, welche v.a. in der Tunica submucosa lokalisiert ist, gewährleistet wird.

Daher ist es wichtig, die physiologischen Veränderungen im Kollagenmetabolismus der darmwandeigenen extrazellulären Matrix nach operativen Eingriffen zu kennen, da sie wesentlich die mechanische Anastomosenstabilität beeinflussen.

Im Folgenden sollen vielversprechende, den regenerativen Prozess der Anastomosenheilung unterstützende und verstärkende Möglichkeiten erläutert werden.

\subsubsection{Einfluss lokaler Faktoren}

Waninger et al. (1992) konnten in ihren Untersuchungen zeigen, dass eine bessere Heilung bei kleineren Stichabständen mit mäßiger Fadenspannung erreicht werden kann. Hierbei kommt es durch zu starke Fadenspannung zu einer geringeren Gewebeperfusion, die anscheinend einen steigernden Einfluss auf die proteolytische Aktivität hat (Jonsson und Hogstrom (1992)). Andersen et al. (1989) konnten nachweisen, dass der Einfluss des Nahtmaterials und der Technik während der 
Heilung insgesamt eine untergeordnete Rolle spielt. Es zeigt sich auch kein Vorteil bei einreihig zu zweireihig genähten Anastomosen (Goligher et al. (1977), Nahai et al. (1977), Sarin und Lightwood (1989), Yesilkaya et al. (1985)). Weitere Untersuchungen konnten ebenfalls keinen wesentlichen Unterschied zwischen der Nutzung von unterschiedlichem Fadenmaterial feststellen.

Chirurgische Anastomosen im Dickdarmbereich sind, abhängig von Ihrer Höhe, bis heute mit erheblichen hohen Risiken der Entwicklung einer Anastomoseninsuffizienz konfrontiert. Für den unteren Gastrointestinaltrakt gilt, umso tiefer die Anastomose angelegt wird, desto höher ist das Risiko der Entstehung einer Anastomoseninsuffizienz. Die Insuffizienzraten liegen hier bei 0,5-1\% im Bereich des rechten Hemikolons, und bei bis zu 8-23 \% bei tiefen kolorektalen Anastomosen nach onkologischen Resektionen (Law und Chu (2004), Bokey et al. (1995), Graf et al. (1991)). Bei Rektumanastomosen besteht bei Insuffizienzen eine Mortaltät von mehr als 20\% (Alberts et al. (2003)).

Die deutlich höhere Inzidenzrate von Insuffizienzen im Bereich des Kolorektums im Vergleich zu Magen- und Dünndarmanastomosen wird, neben den durchblutungsbedingten Unterschieden, auf die deutlich höhere bakterielle Kontamination, sowie die größere Masse des intraluminalen Darminhaltes zurückgeführt (Thornton und Barbul (1997)).

Die Einhaltung einer postoperativen Nüchternheit ist nicht notwendig. Die intestinale Anastomose ist primär luft- und wasserdicht genäht und bedarf keiner „Ruhigstellung“ zur sicheren Heilung. Der Darm transportiert bereits wenige Stunden postoperativ intestinales Sekret über die Anastomose. Die enterale Ernährung der Patienten kann daher ohne erhöhte Gefahr einer Anastomoseninsuffizienz postoperativ frühzeitig begonnen werden. Dies wird im klinischem Alltag bei der sogenannten fast track surgery umgesetzt. In randomisierten Studien konnte gezeigt werden, dass sich die Darmfunktion durch die Vermeidung einer parenteralen Flüssigkeitszufuhr schneller erholt und der Krankenhausaufenthalt verkürzt wird (Ljungqvist O und Soreide E (2003), Wilmore D W und Kehlet H (2001)).

\subsection{Anastomosenprotektion am Gastrointestinaltrakt}

Um die Zahl von Anastomoseninsuffizienzen zu reduzieren, wurden in der Vergangenheit verschiedene operative Techniken und perioperative Maßnahmen entwickelt. 
Präoperative orthograde Darmspülungen, perioperative Antibiotikaprophylaxe, temporäre postoperative parenterale Ernährung und postoperative Eiweißsubstitution werden oft sogar planmäßig in der klinischen Praxis durchgeführt. Des Weiteren wurden medikamentöse, hormonelle und lokal desinfizierende Methoden beschrieben (Erythropoetin, kurzkettige Fettsäuren, Glutamin, Povidone, Jod, Pentoxifyllin) (Kaemmer et al. (2010), Netta et al. (2010), Girgin et al. (2009), Ustek et al. (2005), Tireli et al. (2003)). Unterschiedliche biologische und künstliche Materialien und Gewebe zur Einscheidung von Anastomosen wurden erprobt (Tabelle 1). Zuletzt konnte allerdings keine dieser Methoden in die klinische Verbreitung gelangen und die Inzidenzrate an Anastomoseninsuffizienzen am Kolorektum reduzieren.

Tabelle 1. Verstärkung von Kolonanastomosen durch biologische und synthetische Materialien. Übersicht über klinische und experimentelle Studien.

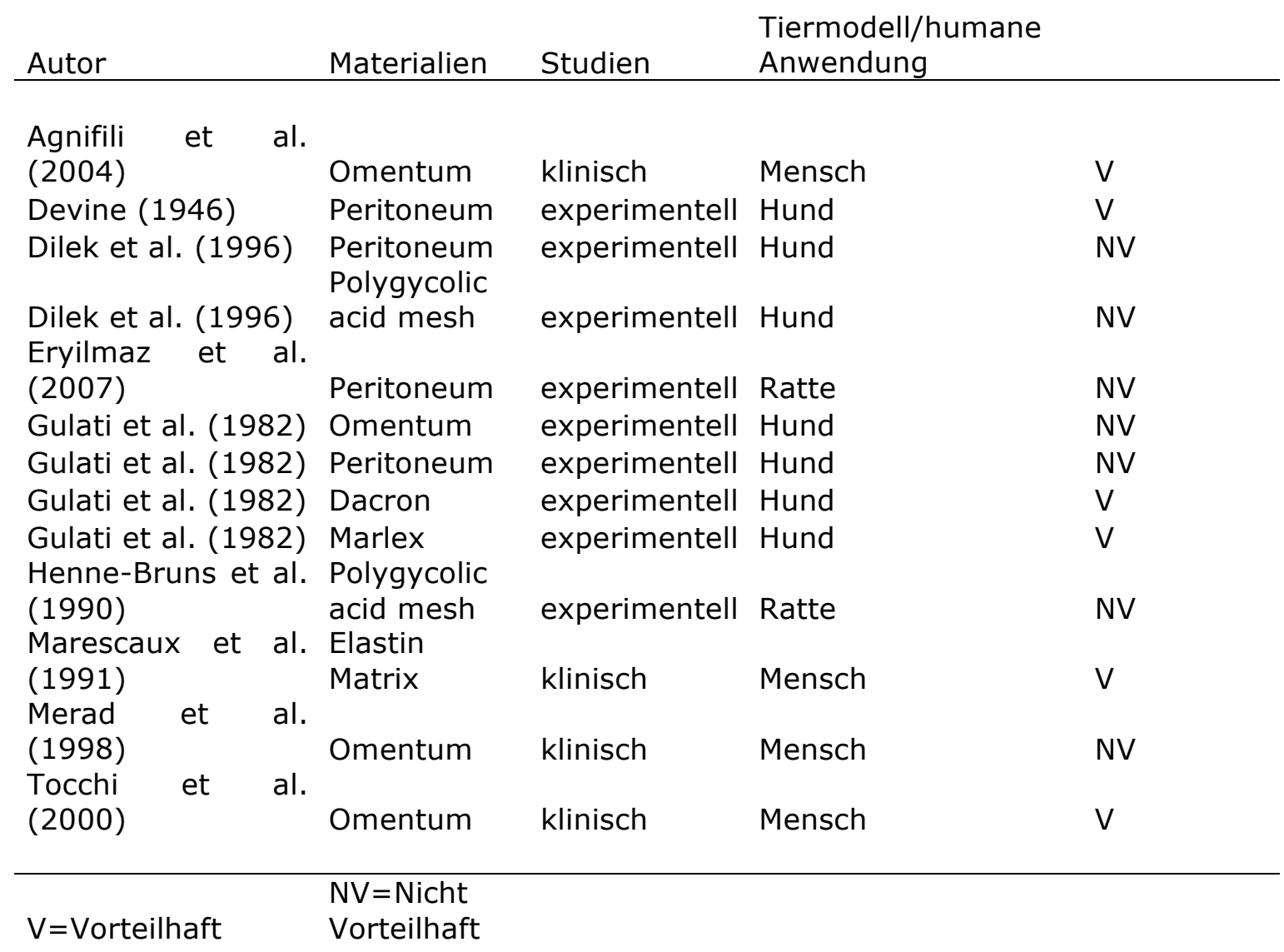

\subsection{Aktueller Stand der Wissenschaft}

Heilungs- und Regenerationsprozesse an gastrointestinalen Hohlorgangen und deren Störungen durch verschiedene Einflussfaktoren spielen eine grundlegende Rolle für die Entstehung chirurgischer Komplikationen, wie z.B. gastrointestinaler 
Anastomoseninsuffizienzen und deren Folgen für die Entstehung chirurgisch wichtiger Krankheitsbilder.

Anastomoseninsuffizienzen stellen eine Hauptkomplikation in der kolorektalen Chirurgie dar und sind der größte und wichtigste Grund für die Morbidität und Mortalität nach darmchirugischen Eingriffen. Je tiefer die kolorektalen Anastomosen angelegt werden, desto höher wird das Risiko der Entwicklung einer postoperativen Anastomosendehiszenz aufgrund der schlechter werdenden Durchblutungssituation und Gefahr eines manuell technischen Anastomosenfehlers durch die erschwerte operative Zugänglickeit des Operationsgebietes ( Law und Chu (2004), Graf et al. (1991), Bokey et al. (1995)).

Unterschiedlichste Methoden werden angewandt, um die Versagensrate der Anastomosen zu reduzieren. Hierzu gehören die präoperativ entleerenden Darmvorbereitungen, perioperative antibiotische Prophylaxe, postoperative parenterale Ernährung sowie die sorgfältige atraumatische chirurgische Präparationstechnik insbesondere bei Patienten mit einem hohen Risiko für eine Anastomosenundichtigkeit.

Neben diesen verschiedenen Möglichkeiten sind ergänzende Methoden zur Erhöhung der Stabilität der Darmwandanastomosen wünschenswert.

Für die Unterstützung und Verstärkung der regenerativen Heilungsprozesse beanspruchen die Anastomosen umhüllenden künstlichen und biologischen Transplantate für sich einen hohen Nutzen (Marescaux et al. (1991)).

Einen vielversprechenden Ansatz für den Schutz von gastrointestinalen Anastomosen stellen anastomosenabdichtende biologische extrazelluläre Matrices ( ECM ) wie Small Intestinal Submucosa ( SIS ) dar. In den vergangenen Jahren konnten unterschiedliche experimentelle Untersuchungen beachtliche Erfolge für die Nutzung von SIS als biologisches Grundgerüst für den Gewebeersatz für Gefäße, Harnblase, Ösophagus, Gallengänge, Dünn- und Dickdarm erzielen (Ueno et al. (2007 a), Kropp et al. (1996), Badylak et al. (1989), Rosen et al. (2002), Demirbilek et al. (2003), Badylak et al. (2000)).

In der folgenden Arbeit wird die unterstützende Wirkung von SIS auf Heilungsprozesse von intestinalen Anastomosen experimentell am Tiermodell des Schweins untersucht. 


\subsection{Extrazelluläre Matrices ( ECM )}

ECM sind aus natürlichen biologischen Geweben gewonnene Matrices, die in ihren Herkunftsgeweben auf dem Raum zwischen den einzelnen Zellen, dem sogenannten Interzellularraum, beschränkt sind. ECM werden von den ortsursprünglichen Zellen der jeweiligen Organ- und Gewebestrukturen hergestellt. Sie sichern durch ihre dreidimensionale Struktur und ihre Komposition aus unterschiedlichen bioaktiven Molekülen wichtige Funktionen der interzellulären Kommunikation und der Kommunikation der ortsständigen Zellen mit der äußeren Umgebung der Gewebestrukturen (Kleinman et al. (2003), Rosso et al. (2004), Brown und Dejana (2003)). Sie nehmen grundlegenden Einfluss auf Formgestaltung, Zugfestigkeit, Elastizität und Wassergehalt der Gewebe und Organe. ECM übernehmen wichtige Funktionen in der Signaltransduktion zwischen Zellen, ihnen konnte zudem eine wesentliche Beeinflussung von Wundheilungsprozessen zugeschrieben werden (Hodde (2002), Nihsen et al. (2008)). Damit stellen sie das ideale natürliche Grundgerüst für die Erneuerung und Wiederherstellung von Geweben und Organen dar (Bissell und Aggeler (1987)). Die dreidimensionale Konfiguration der die ECM ausmachenden struktur- und funktionsgebenden Moleküle sind aktuell noch nicht in ausreichendem Maße charakterisiert, so dass es bis heute nicht möglich ist, ECM künstlich herzustellen. Sowohl in-vitro- als auch in-vivo-Versuche konnten nachweisen, dass einzelne Bestandteile der ECM, wie bestimmte Kollagenstrukturen, Fibronectin, Laminin, Hyaluronsäure und verschiedene Wachstumsfaktoren, in isolierter Form das Zellwachstum und die Zelldifferenzierung beschleunigend beeinflussen (Grinnell et al. (1987), Hu et al. (2009), Pellegrini (2001), Kubo und Kuroyanagi (2003)). Zusätzlich wurden experimentell bereits verschiedene ECM, die z.B. aus der Haut, dem Dünndarm, der Blase, dem Pankreas und anderen Geweben hergestellt wurden, als Bioscaffolds zur Unterstützung des Remodelings der Gewebe unterschiedlicher Organsysteme in einer Vielzahl von Versuchen im Rahmen des Tissue Engineerings untersucht (Kochupura et al. (2005), Meyer et al. (1998), Pahari et al. (2006),Badylak et al. (2000)).

\subsubsection{Small Intestinal Submucosa}

Eine der am häufigsten und besten untersuchten und derzeit auch im Handel erhältlichen ECM ist die aus dem Schweinedünndarm hergestellte SIS. SIS ist eine biodegradierbare, azelluläre, nicht immunogene dreidimensionale Gewebematrix, die 
mittels eines mechanischen und chemischen Herstellungsprozesses aus der Submucosa des porcinen Dünndarms hergestellt wird (Badylak et al. (1989)). Sie besteht aus nativ konfigurierten, konservierten Kollagenen, Glycoproteinen und Proteoglycanen (Hodde (2002)). SIS enthält zusätzlich verschiedene aktive Wachstumsfaktoren wie Vascular Endothelial Growth Factor (VEGF), Transforming Growth Factor-1 (TGF-1) und Fibroblast Growth Factor-2 (FGF-2), die nachweislich beschleunigende Wirkungen auf Wundheilungsverläufe ausüben (Hodde (2002), Voytik-Harbin et al. (1997), Hodde et al. (2001)). Aufgrund ihrer membranösen Struktur mit einer Schichtdicke von 0,1 bis $0,2 \mathrm{~mm}$, ihrer fehlenden Immunogenität, ihrer ursprünglichen intestinalen Herkunft, sowie der biologisch aktiven Funktion im Rahmen von Regenerationssprozessen, stellen SIS ein vielversprechendes biologisches Grundgerüst für die Unterstützung von Wundheilungsverläufen am Gastrointestinaltrakt dar.

Dabei entstehen denkbare Verwendungsmöglichkeiten von SIS für die Umhüllung von Risikoanastomosen am Gastrointestinaltrakt und für den Ersatz von gastrointestinalen Hohlorganen im Sinne des intestinalen Tissue Engineerings.

Nachdem das SIS implantiert ist, reichern sich Zellen und Blutgefässe des Patientengewebes schnell auf dem Implantat an. SIS liefert das Gerüst oder die Matrix für das kontinuierliche Einwachsen und die Differenzierung vom Binde- und Deckgewebe sowie Anlagerung, Organisation und Reifung von ECM Komponenten. Das Ergebnis ist eine Remodellierung des an der Eingriffsstelle originär typischen Gewebes. Dieses Phänomen wird auch als intelligente Gewebe-Remodulierung bezeichnet.

Eine Remodellierung ist erfolgt, wenn Implantat und Eigengewebe nicht mehr voneinander unterscheidbar sind. Das SIS verfügt während der Phase der Remodellierung über eine ausreichende mechanische Stärke, um das Gewebe zu stützen, und dient als Gerüst für den raschen und gezielten Gewebeaufbau. Anders als synthetisch hergestellte Implantate, die sich einkapseln und immunogen wirken, wird SIS schnell von körpereigenen Zellen, Gewebe und Blutgefässen infiltriert. 


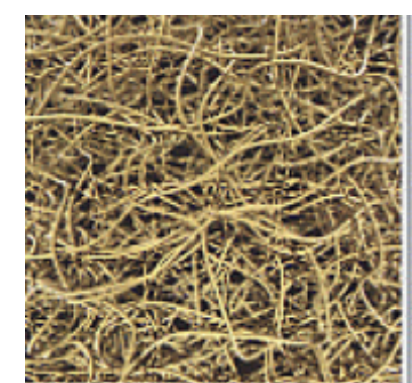

Nach der Implantation beginnt das umliegende Gewebe in die SIS-Matrix Zellen und Nährstoffe zu liefern.

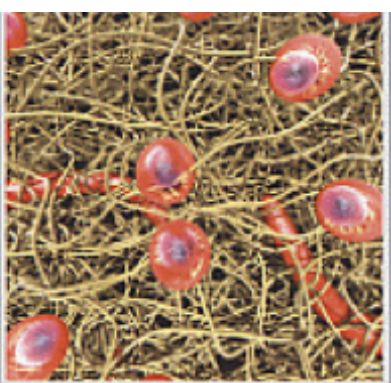

Die Zellen wachsen schnell in die SIS-Matrix ein. Es folgt Kapillarenwochstum, wodurch weitere Nahrstoffe und Zellen in die Matrix gelangen

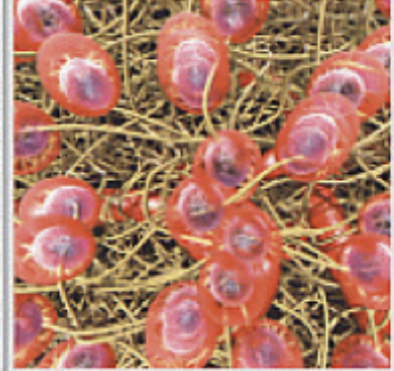

SIS wird fortschreitend ersetzt, das eigene Gewebe verstarkt sich und die schwochen Stellen werden wieder aufgebaut.

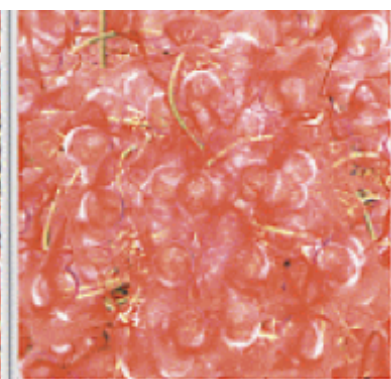

Das körpereigene Gewebe ist vollständig in die Operationsstelle eingewachsen, wahrend SIS weiterhin die notwendige Gewebeunterstützung aufrecht erhält.

Abbildung 4. Rasterelektronenmikroskopische Aufnahme vom Einwachsen der Matrix ( Surgisis R (2010) )

\subsubsection{Bisherige Evidenz des Einflusses von SIS auf gastrointestinale Heilungsprozesse}

In den vergangenen Jahren konnten unterschiedliche Studien beachtliche Erfolge mit der Verwendung von SIS erzielen. Das SIS kam hier vor allem als Gewebeersatz zum Einsatz.In unterschiedlichen experimentellen Untersuchungen konnte in vivo gezeigt werden, dass es an gastrointestinalen Hohlorganen auf der Grundlage von porcinem SIS als Bioscaffold möglich ist, ein Remodeling der wiederhergestellten luminalen Wandungen mit weitgehender Rekonstruktion der natürlichen anatomischen Form und der physiologischen Funktion zu erreichen (Badylak et al. (2000), Rosen et al. (2002), Chen und Badylak (2001),Marescaux et al. (1991), De la Fuente et al. (2003), Ueno et al. (2007 b), Souza Filho et al. (2005), De Ugarte et al. (2004), Ansaloni et al. (2006), Lopes et al. (2006), Wang et al. (2005), Demirbilek et al. (2003)).

Chen und Badylak (2001) setzten in einer tierexperimentellen Studie bei 23 Hunden partielle Dünndarmdefekte und verschlossen diese mit einem SIS Patch. 20 Versuchstiere überlebten bis zum Zeitpunkt der elektiven Sektion ohne intestinale Funktionsstörungen. Die histologischen Untersuchungen zeigten eine epitheliale Mucosaschicht, unterschiedliche Anzahl von glatten Muskelzellen, Schichten von Kollagen und eine Bedeckung mit Serosa.

Diese Studie deutete damit an, dass SIS-Patches für die Regeneration am Dünndarm verwendet werden können. Ähnliche Ergebnisse konnten durch weitere unterschiedliche Studien erzielt werden (Ueno et al. (2007 a), Souza Filho et al. (2005), De Ugarte et al. (2004), Ansaloni et al. (2006)). Andererseits sind in der 
Literatur deutlich unterschiedliche Abweichungen an anatomischer und funktioneller Regeneration berichtet worden (Tabelle 2). Eine nahezu vollständige anatomiegerechte Rekonvaleszenz wurde für Ösophagus- und Dünndarmwand nachgewiesen. Auf der Grundlage von SIS konnten hier der Wiederaufbau von Tunica mucosa und Tunica muscularis innerhalb von drei bis sechs Monaten in vivo gezeigt werden (Badylak et al. (2000), Chen und Badylak (2001),Ansaloni et al. (2006), Lopes et al. (2006)). Am Magen der Ratte konnte, neben der Wiederherstellung von Mucosa und Muskularis innerhalb von sechs Monaten, auch die anatomische und funktionelle Heilung der nervalen Magenwandversorgung im Bereich der rekonstruierten Areale festgestell werden [Ueno et al. (2007 b)]. Am Dünndarm wurde lediglich nur eine geringe Erneuerung der Mukosa und ein vollständiges Fehlen einer Muskelschicht im wiederhergestellten Areal festgestellt (Souza Filho et al. (2005),De Ugarte et al. (2004)).

Tabelle 2. Strukturelle Regeneration gastrointestinaler Hohlorgane auf Basis von ECM als Bioscaffolds

\begin{tabular}{ll} 
Autor Lokalisation Tiermodell & $\begin{array}{l}\text { Strukturelle } \\
\text { Regeneration } \\
\text { Mukosa }\end{array}$ \\
\hline
\end{tabular}
Muskularis Nerv

\begin{tabular}{|c|c|c|c|c|c|}
\hline $\begin{array}{l}\text { Badylak et al. } \\
(2000)\end{array}$ & Ösophagus & Hund & + & + & NA \\
\hline Lopes et al. (2006) & Ösophagus & Ratte & + & + & + \\
\hline $\begin{array}{l}\text { Ueno et al. } \\
\text { Ueno }\end{array}$ & Magen & Ratte & $(+)$ & - & - \\
\hline$(2007 b)$ & Magen & Ratte & + & + & + \\
\hline $\begin{array}{l}\text { Rosen et al. (2002) } \\
\text { De Ugarte et al. }\end{array}$ & Gallengang & Hund & + & - & NA \\
\hline $\begin{array}{l}\text { (2004) } \\
\text { Souza Filho et al. }\end{array}$ & Duodenum & Ratte & $(+)$ & - & NA \\
\hline $\begin{array}{l}(2005) \\
\text { Demirbilek et al. }\end{array}$ & Duodenum & Hund & $(+)$ & - & NA \\
\hline $\begin{array}{l}\text { (2003) } \\
\text { Chen und Badylak }\end{array}$ & Jejunum & Kaninchen & + & - & NA \\
\hline $\begin{array}{l}\text { (2001) } \\
\text { Ansaloni et al }\end{array}$ & Dünndarm & Hund & + & + & NA \\
\hline$(2006)$ & Ileum & Ratte & + & + & + \\
\hline Wang et al. (2005) & Ileum & Ratte & + & $(+)$ & NA \\
\hline $\begin{array}{l}\text { Ueno } \\
(2007 a)\end{array}$ et al. & Zäkum & Ratte & + & + & + \\
\hline $\begin{array}{l}+=\text { Komplette } \\
\text { Regeneration }\end{array}$ & $\begin{array}{l}(+)=\text { Partielle } \\
\text { Regeneration }\end{array}$ & $\begin{array}{l}\mathrm{NA}=\text { Nicht } \\
\text { angegeben }\end{array}$ & & & \\
\hline
\end{tabular}




\section{Fragestellung}

Es schien erfolgsversprechend und logisch, die erfolgreichen Ergebnisse mit der Verwendung von SIS auf weitere Untersuchungen auszuweiten und eine Untersuchung zu entwerfen, die sich auf die Frage konzentriert, welche Wirkung die Umhüllung von Darmanastomosen mit SIS auf die intestinale Anastomosenheilung hat.

Der direkte Einfluss der SIS-Umhüllung einer intestinalen Anastomose auf die Wundheilung der Anastomose wurde bis heute noch nicht untersucht.

Um den Einfluss einer extrazellulären Matrix auf die intestinale Anastomosenheilung zu untersuchen, lag es nahe ein Tiermodell zur Anastomoseprotektion durch SIS an tiefen Kolonanastomosen am Colon descendens am Schwein zu entwickeln.

In dieser Arbeit sollen vor allem folgende Fragen beantwortet werden:

- Zeigen

sich

makroskopische

Unterschiede

der Darmwandanstomosenbeschaffenheit?

- Können histologische Untersuchungen die mikroskopischen Äquivalente einer verbesserten Anastomosenheilung darstellen?

- Kommt es zu einer verbesserten bzw. gesteigerten mechanischen Belastbarkeit der Anastomosen?

- Führt die Umhüllung der Darmwandanastomosen zu einer Lumeneinengung oder zur Entwicklung von Komplikationen wie Strikturen oder Lymphomausbildungen?

- Wie sicher gestaltet sich die Ausführbarkeit der SIS-Umhüllung in einem dem Menschen anatomisch vergleichbaren Tiermodell des Schweins? 


\section{Material und Methoden}

\subsection{Tiermodell}

\subsubsection{Versuchstiere}

Die Studie wurde vom Institut für Tierschutz und den zuständigen Ethikkommissionen der Tierärztlichen Hochschule Hannover sowie der regionalen Kommunalverwaltung des Landes Niedersachsens genehmigt.

Alle Abläufe und Handlungsweisen dieser Studie wurden strikt unter der Einhaltung des deutschen Tierschutzgesetzes durchgeführt unter Einhaltung aller von der National Academy of Sciences ausgearbeiteten und vom National Institutes of Health ( NIH Publikation Nr. 86-23, überarbeitet 1985 ) veröffentlichten Richtlinien des "Guide for Care and Use of Laboratory Animals".

Für die Studienuntersuchungen wurden 18 weibliche deutsche Hausschweine mit einem mittleren Gewicht von 30.6 Kilogramm verwendet. Hierbei lag die Gewichtsspanne zwischen 24 und 39.4 Kilogramm. Die Schweine wurden alle vor dem operativen Eingriff und in regelmäßigen Intervallen während der postoperativen Beobachtungsphase gewogen und das Körpergewicht protokolliert. Die Tiere wurden mit einer standardisierten handelsüblichen Kost und mit Wasser nach Belieben gefüttert. Bei der Kost handelte es sich um Getreideschrot aus der Futtermühle aus der Lieferung für die Tierärztliche Hochschule Hannover.

Sowohl am Tag der Operation zu Beginn der Anästhesieprozedur als auch am ersten Tag nach der Operation wurde den Schweinen intramuskulär eine Antibiose mit Streptomycin/Penicillin $(0.1 \mathrm{ml} / \mathrm{kg}$ Körpergewicht, Streptocomb R, Fa. Streuli, Schweiz ) verabreicht.

\subsubsection{Untersuchungsgruppen}

Die 18 Tiere wurden in 2 Untersuchungsgruppen eingeteilt :

Die Kontrollgruppe beinhaltete die Tiere mit den nicht-umhüllten End-zu-End Standardanastomosen $(n=8)$. Die Studiengruppe enthielt die Tiere bei denen eine mit SIS umhülte End-zu-End Darmanastomose angelegt wurde $(n=10)$. Der Beobachtungszeitraum beider Gruppen betrug 30 Tage.

\subsubsection{Anästhesie und Präoperatives Management}

Vor der Durchführung der Laparotomie wurden alle Schweine gewogen und ihr Körpergewicht dokumentiert. Des Weiteren wurde bei jedem Tier vor der Operation 
die Körpertemperatur gemessen. Die Tiere wurden sowohl präoperativ als auch nach der Operation durchgehend mit einer standardisierten Kost und mit Wasser nach Belieben gefüttert. Den Tieren wurde jedoch 8 Stunden vor der Operation bei freiem Zugang zu Wasser das Futter entzogen. Sowohl am Tag der Operation zu Beginn der Anästhesieprozedur als auch am ersten Tag nach der Operation wurde den Schweinen intramuskulär eine Antibiose mit Streptomycin/Penicillin $(0.1 \mathrm{ml} / \mathrm{kg}$ Körpergewicht, Streptocomb R, Fa. Streuli, Schweiz ) verabreicht. Alle Operationen wurden unter Vollnarkose durchgeführt. Vor Einleitung der Vollnarkose erhielten die Tiere eine intramuskuläre Prämedikation mit Azaperon (2mg/kg/Körpergewicht), Ketaminhydrochlorid (15 mg/kg/Körpergewicht) und Atropin $(0.05$ $\mathrm{mg} / \mathrm{kg} /$ Körpergewicht). Darauffolgend wurde die Anästhesie durch die intravenöse Applikation von Atracurium Besylate und Hypnomidate (10mg/kg/Körpergewicht) vertieft. Anschließend wurden die Tiere intubiert und künstlich mit Isoflurane und einem Gemisch aus Oxygen und Dinitrogen-Oxid beatmet.

\subsubsection{Operativer Versuchsablauf I}

Die Lagerung des Tieres erfolgte in Rückenlage. Das Operationsgebiet des Abdomens wurde steril mit Braunovidon abgewaschen und unter sterilen Kaudelen abgedeckt. Es erfolgte nun eine $25 \mathrm{~cm}$ lange Inzision entlang der Medianlinie des Abdomens im Sinne einer Medianlaparotomie. Nach Eingehen in die Bauchhöhle wurde das Colon descendens bis zum Übergang ins Rektum dargestellt und exploriert.

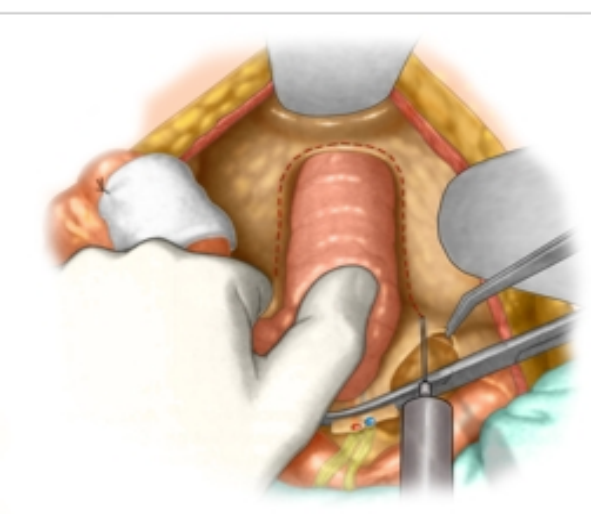

a

Abbildung 5: a freigelegtes Colon descendens in situ $\mathbf{b}$ freigelegtes Colon descendens mit Übergang ins Rektum. ( Verlag: webop Gmbh, Köln (www.webop.de)) 


\subsubsection{Anlage der Anastomose}

Es erfolgte die Transsektion des Colon descendens und präparatorische Entfernung des umliegenden Mesenteriums im Bereich der späteren Anastomose. Der Fäkalinhalt wurde vorsichtig und sorgfältig entfernt und die Darmstümpfe mit einer antiseptischen lodgaze gesäubert und desinfiziert.

Daraufhin erfolgte die Durchführung einer tiefen End-zu-End DescendoDescendostomie-Anastomose. Dies erfolgte standardisiert unter der Verwendung eines $25 \mathrm{~mm}$ durchmessenden Premium Plus CEEA Stapler der Fa. Covidien, Neustadt, Deutschland.

Innerhalb der Kontrollgruppe wurde die Anastomose ohne Manipulation anatomiegerecht ortsursprünglich in der Abdominalhöhle belassen ohne Umhüllung mit dem SIS Gewebestreifen.

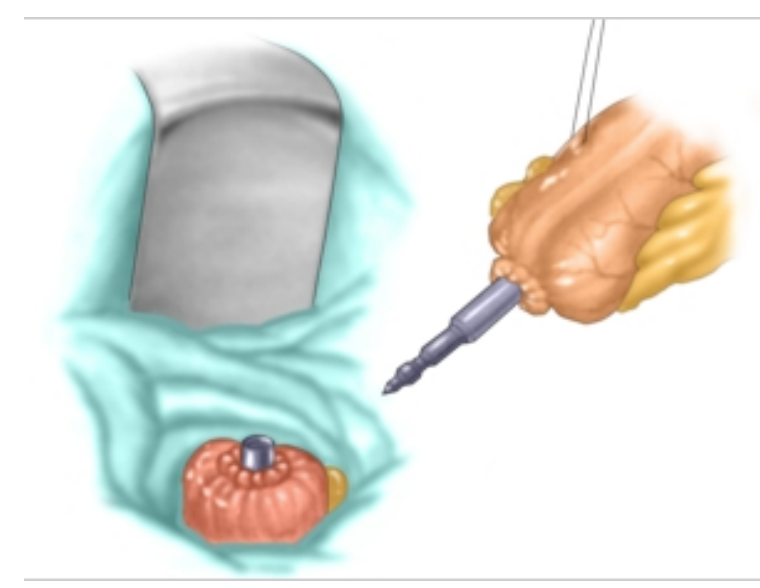

a

Abbildung 6: a Es wird mit dem Rundklammernahtgerät transanal eingegangen und der innenliegende Dorn durch den Rektumstumpf, der zuvor abgestapelt worden war, herausgedreht. Die Gegendruckplatte, die in das Colon descendens eingeknotet worden war, wird aufgesetzt, das Gerät geschlossen und die Anastomose durch Auslösen des Staplers gestapelt. b Anlage einer tiefen Endzu-End-Descendo-Descendostomie-Stapleranastomose. （ Verlag: webop $\mathrm{GmbH}, \mathrm{Köln}$ (www.webop.de) )

\subsubsection{Umhüllung der Anastomose mit SIS}

In der Studiengruppe wurde die standardisierte Stapleranastomose mit einem 75×25 mm großen vier-lagigen SIS Streifen ( Surgisis R, Cook Surgical, Lafayette, IN, USA (2012)) umhüllt. Jede der einzelnen Lagen besteht aus SIS.

Der SIS Streifen wurde zirkulär über der Anastomose um die Darmwand gelegt und mit 3/0 Polysorb (Covidien, Neustadt, Deutschland) in Einzelknopfnahttechnik an der 
Darmwand fixiert. Unter Berücksichtigung der Schwellneigung der Darmwandanastomose in der frühen Phase des Regenerationsprozesses, wurde darauf geachtet, dass bei der zirkulären Umhüllung der Anastomose eine $1 \mathrm{~cm}$ breite Überlappung des SIS Streifens im Bereich der Mesenterialseite vorliegt um eine Dehnung der Darmwand durch die zu erwartende Schwellung zu erlauben. Die überlappenden SIS-Streifenenden wurden im Bereich der Mesenterialseite nicht miteinander verknüpft.

Die Anlage des SIS Streifens dauerte durchschnittlich 10 Minuten. Die Abdominalhöhle wurde nach Bluttrockenheit untersucht und ausgiebig gespült.

Danach wurden in beiden Untersuchungsgruppen die Dickdarmanteile anatomiegerecht wieder neu angeordnet, um eine Ausbildung einer Strangulation zu vermeiden.

Der Verschluß der Abdominalhöhle efolgte schichtgerecht mit resorbierbarem Nahtmaterial Polysorb 2/0 (Covidien, Neustadt, Deutschland). Der Hautverschluss erfolgte mit Klammernahtmaterial. Die Abdominalhöhle wurde nach Anlage der Anastomose in beiden Gruppen auf die gleiche Art und Weise verschlossen.

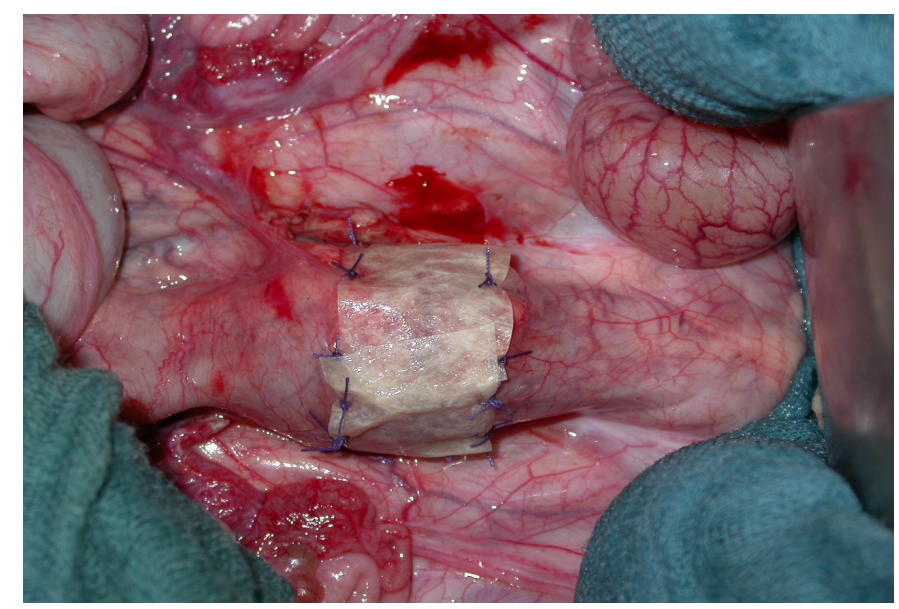

Abbildung 7: Zirkulär gestapelte E/E-Descendo-Descendostomie umhüllt mit einem $75 \times 25 \mathrm{~mm}$ messenden SIS-Patch.

\subsubsection{Postoperativer Verlauf}

Postoperativ gibt es keine Wassertrinkmengenbeschränkung. Am ersten Tag nach der Operation wurde den Schweinen aus beiden Untersuchungsgruppen intramuskulär eine Antibiose mit Streptomycin/Penicillin $(0.1 \mathrm{ml} / \mathrm{kg}$ Körpergewicht, Streptocomb R, Fa. Streuli, Schweiz ) verabreicht. Die Tiere wurden postoperativ genauso wie präoperativ mit einer standardisierten handelsüblichen Kost gefüttert. 


\subsubsection{Operativer Versuchsablauf II}

30 Tage nach dem ersten operativen Eingriff erfogte die Reoperation im Sinne einer neuerlichen Laparotomie zur Beurteilung der Anastomosenheilung und Anastomosenresektion.

Die Reanästhesie erfolgte identisch zur Anästhesieprozedur bei der ersten Operation.

Die Medianlaparotomie erfolgte entlang der bestehenden Hautnaht. Die Bauchhöhle wurde dargestellt, die Anastomose aufgesucht und offengelegt.

Die Abdominalhöhle wurde nach Eröffnung auf Zeichen einer gestörten Anastomosenheilung untersucht. Es wurde auf eine Peritonitis, intraabdominale Abszesse und Fibrinverklebungen geachtet. Die Intaktheit der Anastomose wurde inspiziert und nach Zeichen einer Insuffizienz, pericolitischen Abszessformation, Nekrose, Fistelbildung und Adhäsionen untersucht.

Die Adhäsionen wurden in einem eigens entworfenem Punktesystem von 0 bis 3 makroskopisch bewertet. Dabei wurde anhand einer Punktebewertung (Tab. 3) die Quantität und Qualität der Adhäsionen bestimmt.

Tabelle 3. Makroskopische Punktebewertung der Anastomosenadhäsionen

\begin{tabular}{|l|l|l|l|}
\hline $\begin{array}{l}\text { Adhäsionsrate I } \\
\text { Quantität }\end{array}$ & $\begin{array}{l}\text { Adhäsionsrate II } \\
\text { Qualität }\end{array}$ & \\
\hline 0 & keine Adhäsionen & 0 & keine Adhäsionen \\
\hline 1 & $\begin{array}{l}\text { Adhäsionen mit einer } \\
\text { umliegenden } \\
\text { Organstruktur }\end{array}$ & 1 & $\begin{array}{l}\text { leichte Adhäsionen mit } \\
\text { digitaler Präparation } \\
\text { lösbar ohne Verletzung }\end{array}$ \\
\hline 2 & $\begin{array}{l}\text { Adhäsionen mit zwei } \\
\text { umliegenden } \\
\text { Organstrukturen }\end{array}$ & $\begin{array}{l}\text { fixierte Adhäsionen mit } \\
\text { Präparationsschere } \\
\text { lösbar ohne Verletzung }\end{array}$ \\
\hline 3 & $\begin{array}{l}\text { Adhäsionen mit } \\
\text { mehreren umliegenden } \\
\text { Organstrukturen }\end{array}$ & 3 & $\begin{array}{l}\text { solide Adhäsionen nur } \\
\text { mit Verletzung zu } \\
\text { beseitigen }\end{array}$ \\
\hline
\end{tabular}

\subsubsection{Entnahme des Colon descendens}

Ein $20 \mathrm{~cm}$ langes Darmstück des Colon descendens und Rektums, in deren Mitte sich die Anastomose befindet, wurde für die nachfolgenden Untersuchungen entnommen. Danach erfolgte die Euthanasie durch die intravenöse Injektion von 20 $\mathrm{ml}$ Kaliumchloridlösung ( $2 \mathrm{mmol} / \mathrm{kg} / \mathrm{KM}$ ). 


\subsection{Radiologische Untersuchung}

Nach vorsichtiger Spülung und Säuberung des Darmstücks wurden beide Seiten abgeklemmt. Das proximale Darmsegment wurde vorsichtig kanüliert und das resezierte Colon descendens mit einem wasserlöslichem Kontrastmittel (Gastrografin $\circledR^{\circledR}$, Fa. Schering, Berlin, Deutschland) gefüllt.

Die Durchmesser der Anastomose sowie die der Darmanteile $2 \mathrm{~cm}$ vor und $2 \mathrm{~cm}$ nach der Anastomose wurden durch die Durchführung von digitalen Röntgenaufnahmen ermittelt und notiert.

Für die Röntgenaufnahmen wurde ein Bildanalyseprogramm (Image $\mathrm{J}, \mathrm{NIH}$, Bethesda, USA) verwendet.

\subsubsection{Auswertung}

Die radiologische ex-situ-Auswertung repräsentiert nicht die physiologischen Verhältnisse in vivo. Die Untersuchungsergebnisse werden daher als nachgeahmt bewertet, obwohl die Bedingungen vergleichbar sind. Dennoch erlauben die radiologischen Beobachtungen eine Beurteilung des Grads der Stenose oder Dilatation an der Anastomose.

Für jedes Tier wird ein Anastomosenindex (Al) ausgerechnet (Jansson et al. (1991)):

$$
\mathrm{AI}=\frac{2 \times \text { anastomotic diameter }}{\text { proximal diameter }+ \text { distal diameter }}
$$

Ein geradliniges Darmrohr hat einen Al von 1. Anastomosenstrikturen oder proximale Dilatationen würden zu einer Verkleinerung des Anastomosenindex führen.

Der Prozentsatz der Verringerung des Darmdurchmessers im Bereich der Anastomose wurde folgendermaßen berechnet: $100 \times(1-\mathrm{Al})$. 


\subsection{Berstungsdruckmessung}

Nach sorgfältiger Ausspülung des wasserlöslichen Kontrastmittels werden beide Darmseiten an eine Katheterleitung (18-Ch) durch Tabaksbeutelnaht wasser- und luftdicht angeschlossen.

Die eine Seite wird daraufhin an eine Perfusorspritze ( Perfusor ${ }^{\circledR}, 50 \mathrm{ml}$, Braun, Melsungen, Deutschland), die andere Seite an den GDH 14 AN Digital-Manometer ( Fa. Greisinger, Regenstauf, Deutschland) konnektiert.

Das Darmstück wird unter Wasser getaucht. Luft wird nun manuell per Hand über die Perfusionsspritze infundiert.

Der Druck im Lumen steigt kontinuierlich bis zu einem Maximum an, bei dem Wasserblasen aus einer Stelle der Anastomose aufsteigen und der intraluminale Druck abrupt abfällt.

Der maximal gemessene Druck ist der Berstungsdruck. Der intraluminale Druck wurde in dieser Untersuchung auf weit überphysiologische $200 \mathrm{~mm} \mathrm{Hg}$ begrenzt.

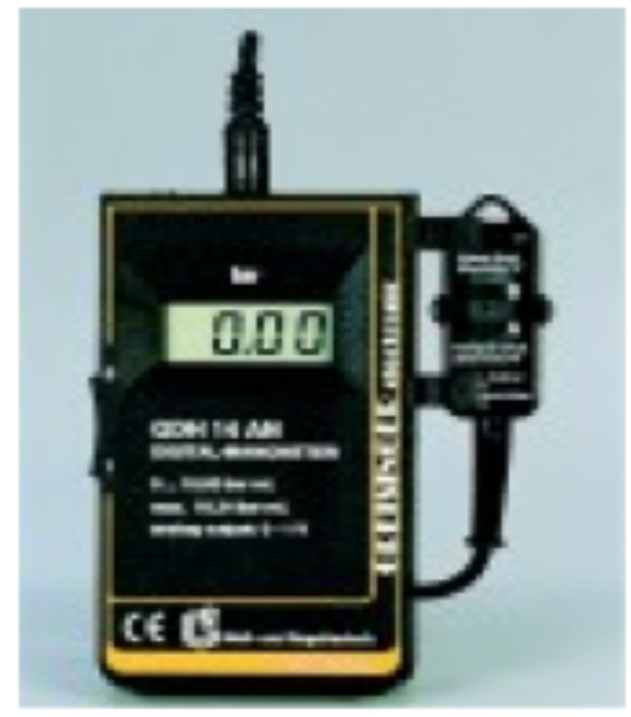

Abbildung 8: GDH 14 AN Digital-Manometer (Fa. Greisinger) zur Berstungsdruckmessung.

\subsection{Makroskopische Untersuchung}

Das Darmpräparat wurde extraluminal während der gesamten Untersuchungs- und Präparationszeit mit einer 0,9 \% Kochsalzlösung feucht gehalten.

Das entnommene Colon descendens wird längs entlang der Mesenterialseite aufgeschnitten.

Als erstes wird die Serosaseite untersucht. Der makroskopische Zustand und die Lageposition des SIS-Streifens wird beurteilt. Dabei wird darauf geachtet, ob der SIS- Streifen in seiner intraoperativ eingebrachten Position verblieben ist oder sich 
gelöst hat und disloziert ist. Zusätzlich wird der SIS-Streifen makroskopisch auf seine Intaktheit überprüft. Dabei wird auf eine Formveränderung des SIS-Streifens in Form von Zusammenziehen und Schrumpfen des Materials geachtet. Weiterhin wird das SIS insbesondere auf eine makroskopisch sichtbare Gefäßeinsprossung auf dem Patch untersucht. Zusätzlich wird das Präparat auf Vorkommen von Darmnekrosen und Fisteln inspiziert.

Danach wird das Präparat umgedreht und die Mukosaoberfläche nach epithelialen Defekten, Mukosanekrosen, Fisteln und Intaktheit der Stapleranastomose untersucht.

\subsection{Histologie}

\subsubsection{Vorbereitung}

Die entnommenen Anastomosen werden für 4 Tage in $4 \%$ - Formalin eingelegt und durch eine Histokinette (Histokinette 2000 Automatic Tissue Protector, Reichert-Jung $\mathrm{GmbH}$, Wien, Österreich) mittels steigender Alkoholreihe (70\%, $80 \%, 98 \%)$ entwässert und fixiert.

Die Paraffinierung erfolgt mit einem Histoembedder (EG1160, Reichert-Jung GmbH, Wetzlar, Deutschland). Die Präparate wurden in einem $90^{\circ}$-Winkel zur Anastomosenlinie in $2 \mathrm{~mm}$ dicke Scheiben geschnitten.

\subsubsection{Hämatoxylin-Eosin-Färbung}

Die Präparate werden jetzt mit Hilfe eines Mikrotoms in $5 \mu \mathrm{m}$ dicke Scheiben geschnitten.

Die zugeschnittenen Präparate werden auf einen Objektträger aufgelegt und für 10 min in Hämalaun-Lösung eingetaucht und darauf gründlich mit Leitungswasser abgespült. In 0,15 \% Eosin-Lösung werden die Präparate für 3-5 min rot angefärbt. Mittels der aufsteigenden Alkohol werden die Proben fixiert. Nach der Färbung stellen sich Bindegewebe, Zytoplasma und Erythrozyten rot, zellkerne blau dar.

\subsubsection{Auswertung}

Die Präparate wurden von einem Pathologen (Dr. Eva Jüttner, Pathologisches Institut, Universität Freiburg) auf die Mukosaabdeckung entlang der Anastomosenlinie, Präsenz einer entzündlichen Reaktion innerhalb der Darmwandschichten, und Quantität des Granulationsgewebes in der Darmwand untersucht. Die Quantität des Granulationsgewebes im Anastomosenbereich wird 
von einem erfahrenen Pathologen semiquantitativ beurteilt. Als mikroskopische Kriterien für das Vorhandensein von Granulationsgewebe werden u. a. Gefäßneubildungen, Fibroblasteneinsprossungen, Kollagenmatrix sowie Makrophageninfiltrationen gewertet. Zur weiteren Graduierung wird ein ScoringSystem von 0 bis 2 angewendet:

$0=$ Minimales Vorhandensein der Granulationsgewebsstrukturen

1 = Moderates, aber deutlich erkennbares Vorhandensein von Kapillaren,

Kollagen, Fibroblasten und Makrophagen

2 = ausgeprägtes zellreiches ("florides") Granulationsgewebe

Zusätzlich wird die mikroskopische Präsenz von Anastomosenabszessen, Darmwandnekrosen, Darmwandfisteln, und Fremdkörperreaktionen als Merkmale einer gestörten Anastomosenheilung untersucht.

\subsection{Statistik}

Sämtliche statistische Daten werden mit Hilfe des Statistikprogrammes Sigmastat $₫$ (Systat Software Inc., Chicago, IL, USA) ausgewertet. Die Berechnungen erfolgen mit Hilfe des Mann-Whitney $U$ sowie dem Chi-Quadrat Test. Die Standardabweichung vom Mittelwert wird als Standard error of the mean (SEM) angegeben. Eine Irrtumswahrscheinlichkeit von $5 \%(p<0,05)$ wird als signifikant angenommen. 


\section{Ergebnisse}

\section{1 Überleben}

Sowohl aus der Kontrollgruppe als auch aus der Studiengruppe verstarben keine Tiere aufgrund von Anastomoseninsuffizienzen oder intraabdominellen Infektionen. Die Tiere aus beiden Untersuchungsgruppen entwickelten keine relevanten klinischen Erkrankungen in Folge einer Anastomosenundichtigkeit oder intraabdominellen Infektion.

Ein Tier aus der Kontrollgruppe entwickelte am 10. postoperativen Tag Anzeichen einer lleussymptomatik des Dickdarms. Die operative Exploration zeigte eine hochgradige Stenose im Bereich der angelegten Darmwandanastomose des Colon descendens.

\subsection{Klinischer Verlauf}

Es wurde die Operationszeit zwischen der Kontroll und Studiengruppe verglichen. Es zeigte sich, dass die Operationszeit in der Studiengruppe mit Umhüllung der Anastomose mit SIS, signifikant länger ausfiel als in der Kontrollgruppe mit der Anlage einer Standardstapleranastomose ( $92 \pm 1,8$ vs. $78 \pm 5,6 \mathrm{~min}, p=0,021$ ).

Ein Tier aus der SIS-Studiengruppe und zwei Tiere aus der Kontrollgruppe entwickelten eine oberflächliche Wundinfektion der Bauchdecke ohne Anzeichen einer systemischen Infektion. Es kam zu keiner Beeinträchtigung der weiteren klinischen Untersuchungsabläufe.

Die beiden Untersuchungsgruppen zeigten postoperativ keinen signifikanten Unterschied in der Gewichtszunahme (7,79 $\pm 0,33 \mathrm{~kg}$ (+25\%) SIS-Gruppe vs. 6,8 \pm $0,57 \mathrm{~kg}(+24 \%)$ Kontrollgruppe). 


\subsection{Makroskopische Untersuchung}

Die makroskopischen Untersuchungen der Bauchhöhle zeigten in beiden Untersuchungsgruppen keine Anastomoseninsuffizienzen, intraabdominelle Abszesse, Fisteln, oder Nekrosen entlang der Anastomose.

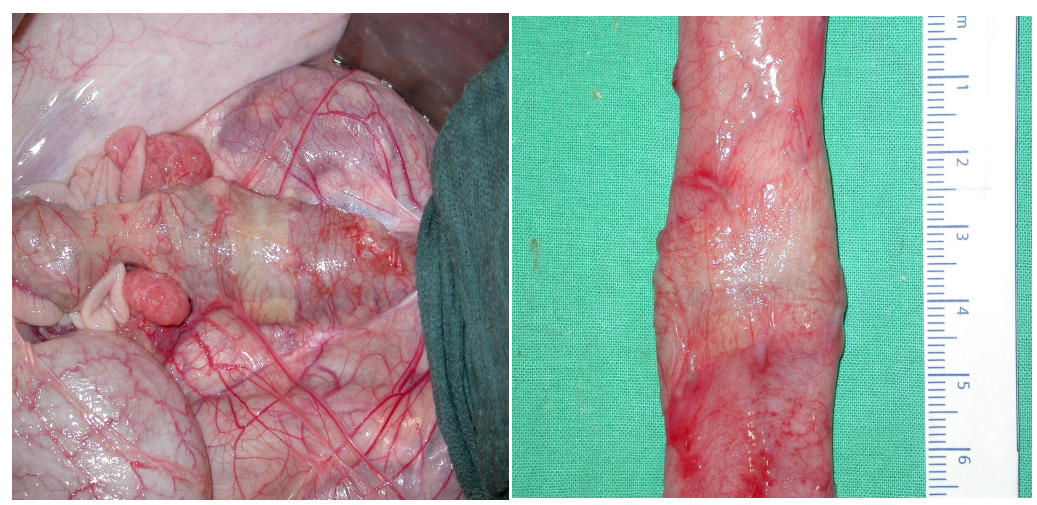

a

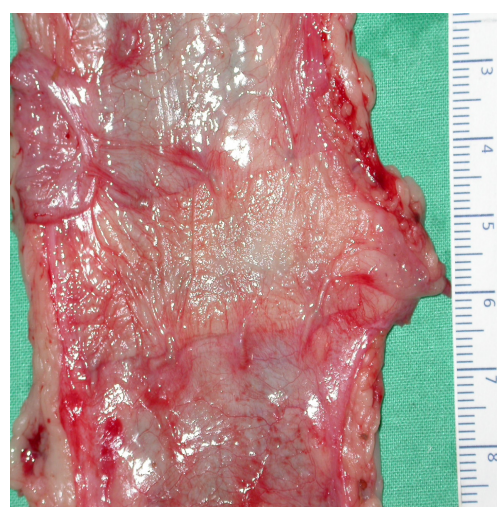

C b

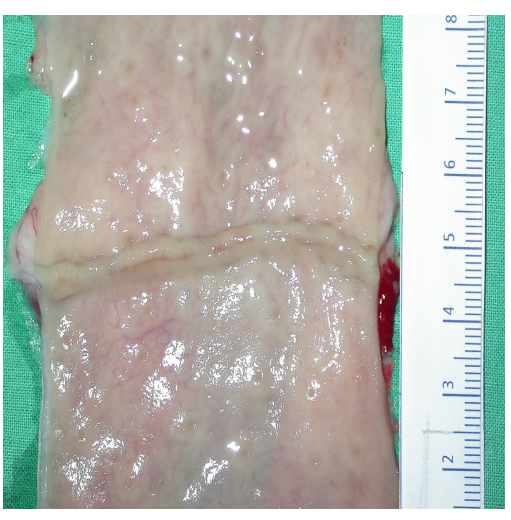

d

Abbildung 9: a SIS-umhüllte E/E-Descendo-Descendostomie am 30. postoperativen Tag in situ ohne erkennbare intraabdominelle Abszesse.b SIS-umhüllte E/E-Descendo-Descendostomie am 30. postoperativen Tag ex situ mit leichter Schrumpfung des SIS-Patches.C Entnommenes Kolon mesenterialseitig längs aufgeschnitten zur makroskopischen Beurteilung. Erkennbarer SIS-Patch auf der Serosaseite. Keine erkennbaren Nekrosen oder Abszesse entlang der Anastomose.d entnommenes Kolon mesenterialseitig längs aufgeschnitten zur makroskopischen Beurteilung. Erkennbare intakte Stapleranastomose auf der Mukosaseite ohne Anzeichen einer Insuffizienz.

Ein Tier aus der SIS-Studiengruppe entwickelte ein $1 \mathrm{~mm}$ durchmessendes Ulkus im Bereich der Mucosaseite der Stapleranastomose (Tab. 5). In der Kontrollgruppe entwickelte ein Tier eine vollständig ausgeprägte Anastomosenstenose (Tab. 5).

Eine Einkapselung und Dislokation der umhüllenden SIS-Patches wurde in zwei Tieren beobachtet (Abb.12). 


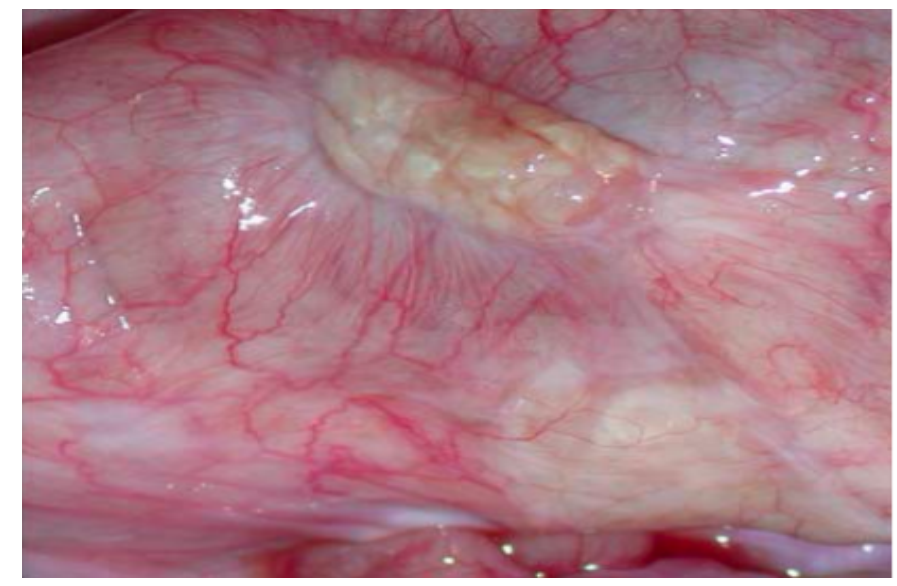

Abbildung 10: Geschrumpfter eingekapselter SIS-Patch über E/E-Descendo-Descendostomie am 30. postoperativen Tag.

Nach 30 Tagen zeigte sich in beiden Gruppen eine häufige Entwicklung von Adhäsionen. In absteigender Häufigkeit waren der Uterus, die Ovarien und das Dickdarmsegment von den Adhäsionen betroffen.

Es zeigten sich in beiden Untersuchungsgruppen keine signifikanten Unterschiede in der Entwicklung von Adhäsionen weder in Qualität $(p=0,929)$ oder Quantität $(p=0,853)($ Tab. 4).

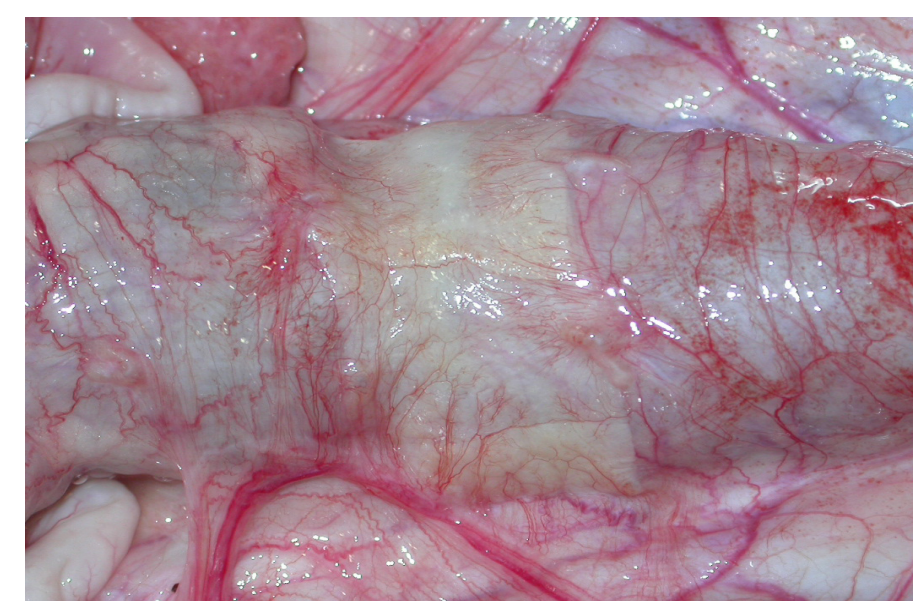

Abbildung 11 : Makroskopischer Aspekt der SIS-umhüllten E/E-Descendo-Descendostomie am 30. postoperativen Tag in situ mit sichtbaren leichten Adhäsionen (Punktescore 1) entlang des Dickdarms und der Ovarien 
Tabelle 4. Makroskopische Auswertung der Anastomosenadhäsionen

Tier Nr. Adäsionsrate I Adhäsionsrate II Quantität* Qualität**

\section{Studiengruppe SIS}

1

2

3

4

5

6

7

8

9

10

\section{Mean}

SEM

\section{Kontrollgruppe}

1
2
3
4
5
6
7
8
Mean
SEM

SEM

$$
\begin{aligned}
& 2 \\
& 3 \\
& 0 \\
& 0 \\
& 0 \\
& 2 \\
& 2 \\
& 2 \\
& 0 \\
& 0
\end{aligned}
$$

1,1

* Adhäsionsrate I:

$0=$ keine Adhäsionen

$1=$ Adhäsion mit einer Struktur;

2=Adhäsion mit zwei Strukturen;

3=Adhäsionen mit mehreren Strukturen

** Adhäsionsrate II:

$0=$ keine Adhäsionen;

$1=$ leichte Adhäsionen;

2=fixierte Adhäsionen;

$3=$ solide Adhäsionen nur mit Verletzung zu beseitigen 
In 6 von 10 Tieren der SIS-Studiengruppe stellte sich auch nach 30 Tagen die Anastomose noch komplett gedeckt durch den SIS-Patch dar (Abb. 12).

Eine sichtbare schrumpfende Kontraktion der umhüllenden SIS Patches wurde in 90 \% der umhüllten Versuchstiere evident (Abb.12).

Eine makroskopisch erkennbare Gefäßeinsprossung in das SIS konnte bei allen Tieren der Studiengruppe nachgewiesen werden (Abb. 12).

Tabelle 5. Makroskopische Untersuchungsergebnisse der Anastomosen

\begin{tabular}{llll}
$\begin{array}{lll}\text { Makroskopische } \\
\text { Untersuchung }\end{array}$ & $\begin{array}{l}\text { Studiengruppe } \\
\text { SIS } \mathrm{n}=10\end{array}$ & $\begin{array}{l}\text { Kontrollgruppe } \\
\mathrm{n}=8\end{array}$ & $\mathrm{p}$ \\
\hline & & & \\
Anastomoseninsuffizienz & $0 / 10$ & $0 / 8$ & $\mathrm{~ns}$ \\
Anastomosenulkus & $1 / 10$ & $0 / 8$ & $\mathrm{~ns}$ \\
Intraabdomineller Abszess & $0 / 10$ & $0 / 8$ & $\mathrm{~ns}$ \\
Peritonitis & $0 / 10$ & $0 / 8$ & $\mathrm{~ns}$ \\
Sichtbare Stenose & $0 / 10$ & $1 / 8$ & $\mathrm{~ns}$
\end{tabular}

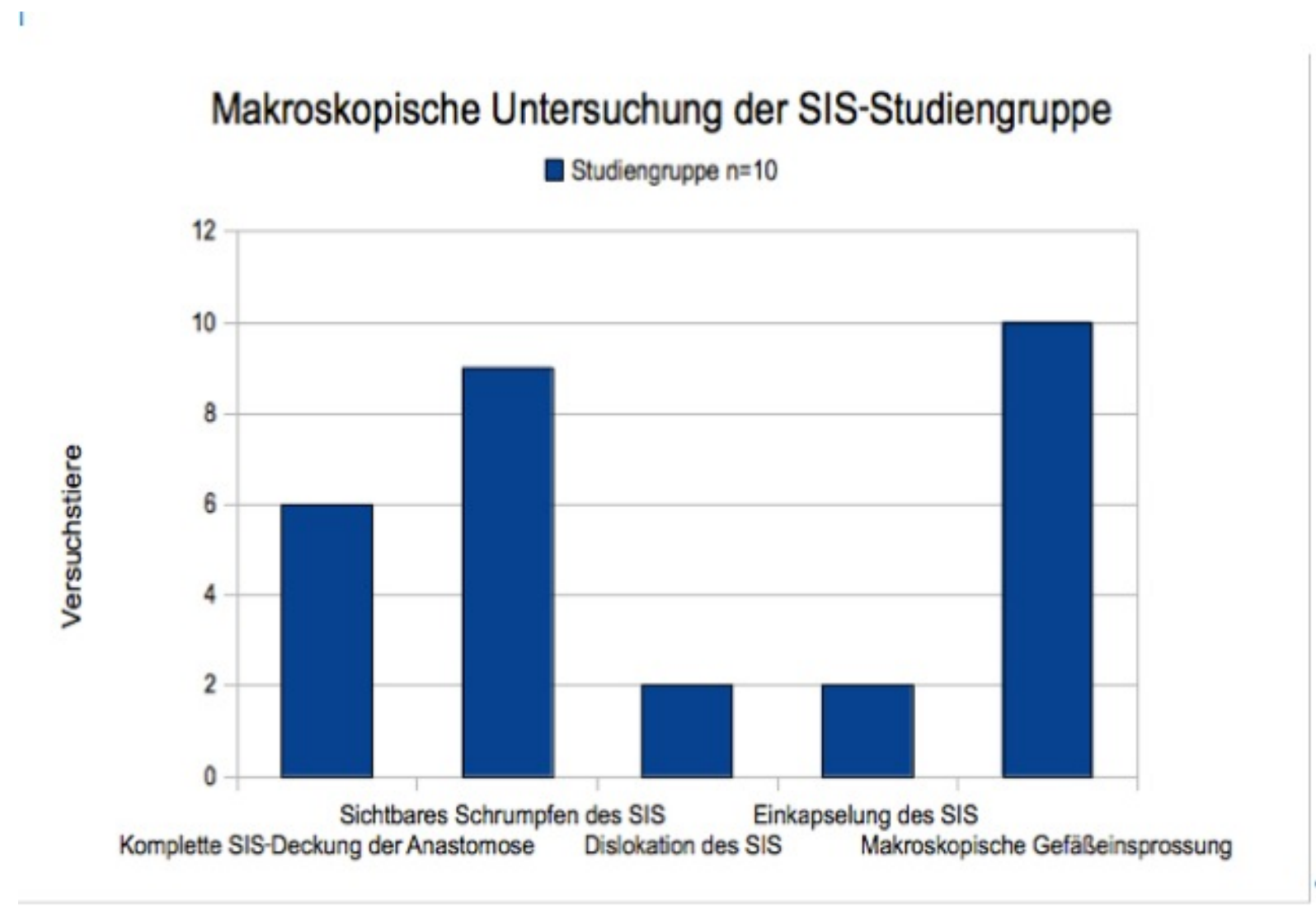

Abbildung 12: Makroskopische Untersuchung der anastomosenumhüllenden SIS-Patches 30 Tage nach Anastomosenumhüllung mit $75 \times 25$ mm vierlagigem SIS. 


\subsection{Berstungsdruck}

In beiden Untersuchungsgruppen zeigten sich in einem Berstungdruckversuch mit einem maximalen intraluminalem Druck von $200 \mathrm{mmHg}$ alle Anastomosen suffizient und wasserdicht.

Es konnten somit keine signifikanten Unterschiede der mechanischen Belastbarkeit der Anastomosen zwischen SIS umhüllten Anastomosen und Standardanastomosen festgestellt werden.

\subsection{Radiologische Auswertung}

Bei der radiologischen Untersuchung konnten in beiden Untersuchungsgruppen keine Fisteln oder Anastomoseninsuffizienzen nachgewiesen werden.

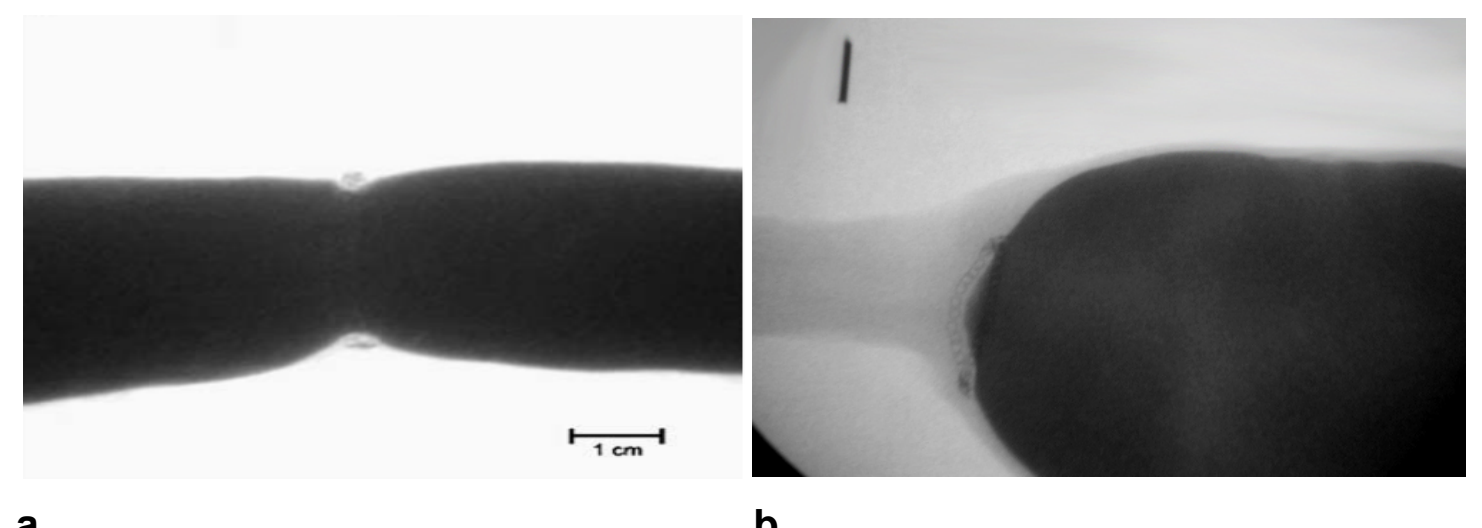

a

b

Abbildung 13: a Röntgenkontrastdarstellung einer SIS-umhüllten E/E-Descendo-Descendostomie am 30. Tag ohne Nachweis einer Anastomoseninsuffizienz.b Erkennbare Anastomosenstenose bei einer Staplerstandardanastomose ohne SIS aus der Kontrollgruppe am 10. postoperativen Tag.

Bezüglich der Anastomosenstrikturen zeigte sich zwischen der SIS Gruppe und der Untersuchungsgruppe kein signifikanter Unterschied.

In der Kontrollgruppe zeigte ein Tier am 10. postoperativen Tag bei einem klinischen lleusbild bei der Röntgenkontrastmitteldarstellung eine vollständige Stenose der Anastomose. Der Anastomosenindex betrug in der SIS Gruppe 0,78 und in der Kontrollgruppe 0,64 ( $p=0,198$, Tab. 6). Der Prozentsatz der Verkleinerung des Anastomosendurchmessers lag in der SIS Gruppe bei $22 \%$ vs. Kontrollgruppe $35 \%$ $(p=0,198$, Tab. 7$)$. 
Tabelle 6: Radiologische Auswertung des Anastomosendurchmesser

\begin{tabular}{lccc}
$\begin{array}{l}\text { Radiologische } \\
\text { Untersuchung }\end{array}$ & $\begin{array}{l}\text { Studiengruppe } \\
\text { SIS } n=10\end{array}$ & $\begin{array}{l}\text { Kontrollgruppe } \\
n=8\end{array}$ & $\mathrm{p}$ \\
\hline Fistel & $0 / 10$ & $0 / 8$ & $\mathrm{~ns}$ \\
$\begin{array}{l}\text { Anastomosenindex } \\
\text { Mean }\end{array}$ & 0,78 & 0,64 & $\mathrm{~ns}$ \\
SEM & 0,02 & 0,09 &
\end{tabular}

Tabelle 7 : Radiologische Untersuchungsergebnisse der Anastomosendurchmesser

Tier Nr. Reduktion des

Durchmessers

in Prozent

\section{Studiengruppe SIS}

128,13

$2 \quad 19,23$

$3 \quad 21,65$

$4 \quad 22,96$

$5 \quad 29,34$

$6 \quad 28,68$

$7 \quad 29,04$

$8 \quad 20,32$

$9 \quad 19,27$

$10 \quad 4,30$

Mean 22,29

SEM $\quad 1,88$

\section{Kontrollgruppe}

124,60

$2 \quad 27,65$

$3 \quad 100,00$

$4 \quad 26,16$

$5 \quad 17,30$

$6 \quad 24,12$

$7 \quad 33,76$

$8 \quad 30,66$

Mean 35,53

SEM $\quad 9,37$

$p=0,198$ 


\subsection{Histologie}

Nach Hämatoxylin-Eosin-Färbung wurden alle 18 Darmwandanastomosenpräparate histologisch untersucht.

Eine komplette Deckung der Mukosa konnte in 6 von 10 Tieren in den SIS verstärkten Anastomosen und in 3 von 8 Tieren in den Standardanastomosen nachgewiesen werden $(p=0,447)$. Abb. 16 zeigt oben im Bild die ununterbrochene Deckung der Anastomosenlinie mit Mucosa.

Alle anderen Tiere zeigten kleine Mukosalücken im Bereich der Anastomosenlinie, die mit Granulationsgewebe (Abb. 17 mit Pfeil gekennzeichnet) gefüllt waren.

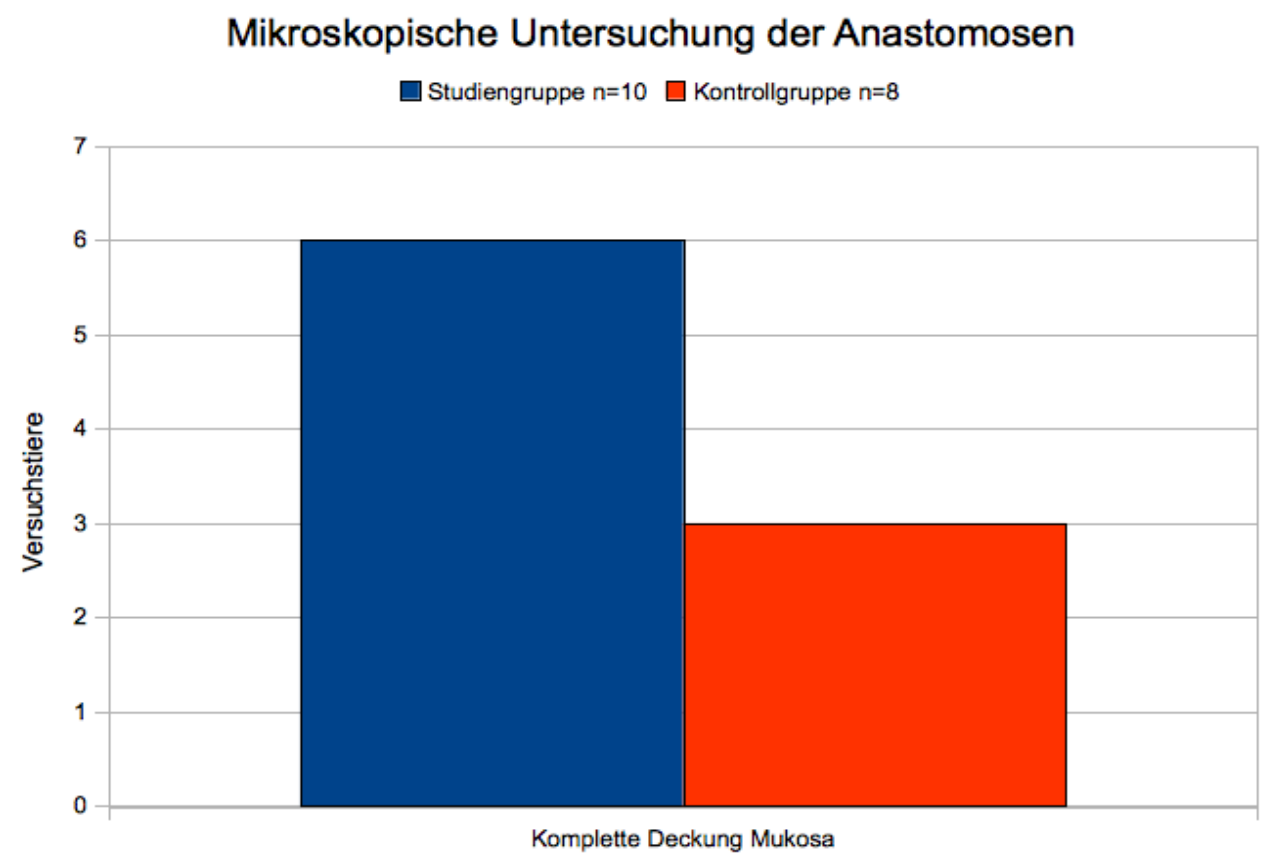

Abbildung 14 : Mikroskopische Untersuchung der Mukosa in beiden Studiengruppen.

In beiden Gruppen waren Entzündungszeichen in allen Darmwandschichten deutlich erkennbar.

Die quantitative Menge an Anastomosengranulationsgewebe war in den mit SIS umhüllten Anastomosen dezent höher im Vergleich zu den Standardanastomosen, ohne jedoch eine statistische Signifikanz zu erreichen $(p=0,263)$. 


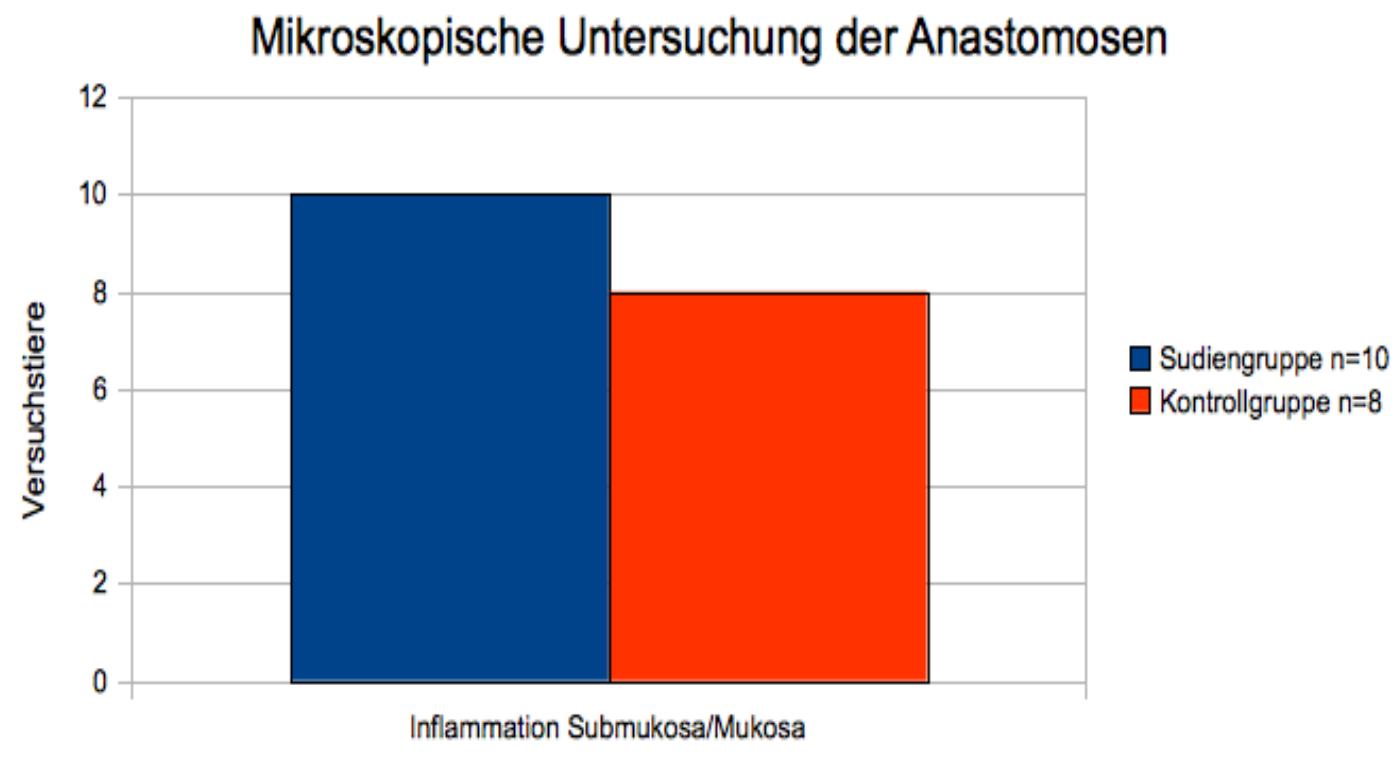

Abbildung 15 : Mikroskopische Untersuchung der Inflammation der Submukosa/Mukosa an den SISumhüllten Anastomosen und in der Kontrollgruppe.

In beiden Untersuchungsgruppen zeigte ein Tier eine Entstehung eines Fremdkörpergranuloms unter Einschluss von Fäkalinhalt. Bei keinem einzigen Tier konnten im Bereich der Anastomosen, Abszesse, Nekrosen oder Fisteln festgestellt werden.

Des Weiteren gab es keine offensichtlichen Unterschiede bei der Wundheilung innerhalb der beiden verglichenen Gruppen.

Im Vergleich der morphologischen Heilungsparameter konnten nach 30

Tagen keine signifikanten Unterschiede zwischen den Versuchsgruppen nachgewiesen werden, wobei allerdings in der SIS-Gruppe der Anteil der komplett mit Mukosa gedeckten Anastomosen sowie die Quantität von Granulationsgewebe in der Anastomose erhöht war (Tab. 8). 
Tabelle 8: Mikroskopische Untersuchungsergebnisse der Anastomosen

\begin{tabular}{llll} 
Mikroskopische Untersuchung & $\begin{array}{l}\text { Studiengruppe } \\
\text { SIS } \mathrm{n}=10\end{array}$ & $\begin{array}{l}\text { Studiengruppe } \\
\mathrm{n}=8\end{array}$ & $\mathrm{p}$ \\
\hline Komplette Deckung der Mukosa & $6 / 10$ & $3 / 8$ & $\mathrm{~ns}$ \\
Inflammation Mukosa & $10 / 10$ & $8 / 8$ & $\mathrm{~ns}$ \\
Inflammation & $10 / 10$ & $8 / 8$ & $\mathrm{~ns}$ \\
Submukosa/Mukosa & $0 / 10$ & $0 / 8$ & $\mathrm{~ns}$ \\
Abszess & $0 / 10$ & $0 / 8$ & $\mathrm{~ns}$ \\
Nekrose & $0 / 10$ & $0 / 8$ & $\mathrm{~ns}$ \\
Fistel & 1,7 & 1,38 & $\mathrm{~ns}$ \\
Granulationsgewebe Quantität* & $1 / 10$ & $\mathrm{~ns}$ \\
Fremdkörperreaktion & $1 / 10$ & & \\
\hline *Punktesystem 0-2 & & $1=$ moderat & $2=$ ausgeprägt
\end{tabular}

Histologisch konnte eine gesteigerte vaskuläre Neueinsprossung (Abb. 18 blauer Pfeil) sowie eine gesteigerte Einströmung von Fibroblasten (Abb. 18 schwarzer Pfeil) und Lymphozyten in den Anastomosenbereich der SIS-umhüllten Anastomosen beobachtet werden.

In Abbildung 16 können alle Darmwandschichten beurteilt werden. Man erkennt, dass die Mukosaschicht vollständig die Anastomose bedeckt (blaue Pfeile). Der SISStreifen liegt unter der Serosaschicht (siehe Pfeil in Abb. 16, zehnfache Vergrösserung ). Lymphozyten (Abb. 19 schwarzer Pfeil) und Makrophagen (Abb.19 blauer Pfeil) infiltrieren den SIS-Patch ohne Anzeichen für das Vorliegen einer Infektion oder eines Abzesses.

Zelleinströmung durch die aktivierten Fibroblasten und Makrophagen war in der gesamten Schichtdicke des vier-lagigen SIS-Patches sichtbar (Abb. 18 und 19).

Die SIS-Streifen zeigten zusätzlich eine ausgeprägte mikroskopische Gefäßeinsprossung (Abb. 18 blauer Pfeil). Auch in Abbildung 16 und 18 erkennt man deutlich sichtbare kleinere Kapillaren und Gefäße mit gefüllten Blutzellen als Zeichen der zellulären Einwanderung von Lymphozyten und Makrophagen. 


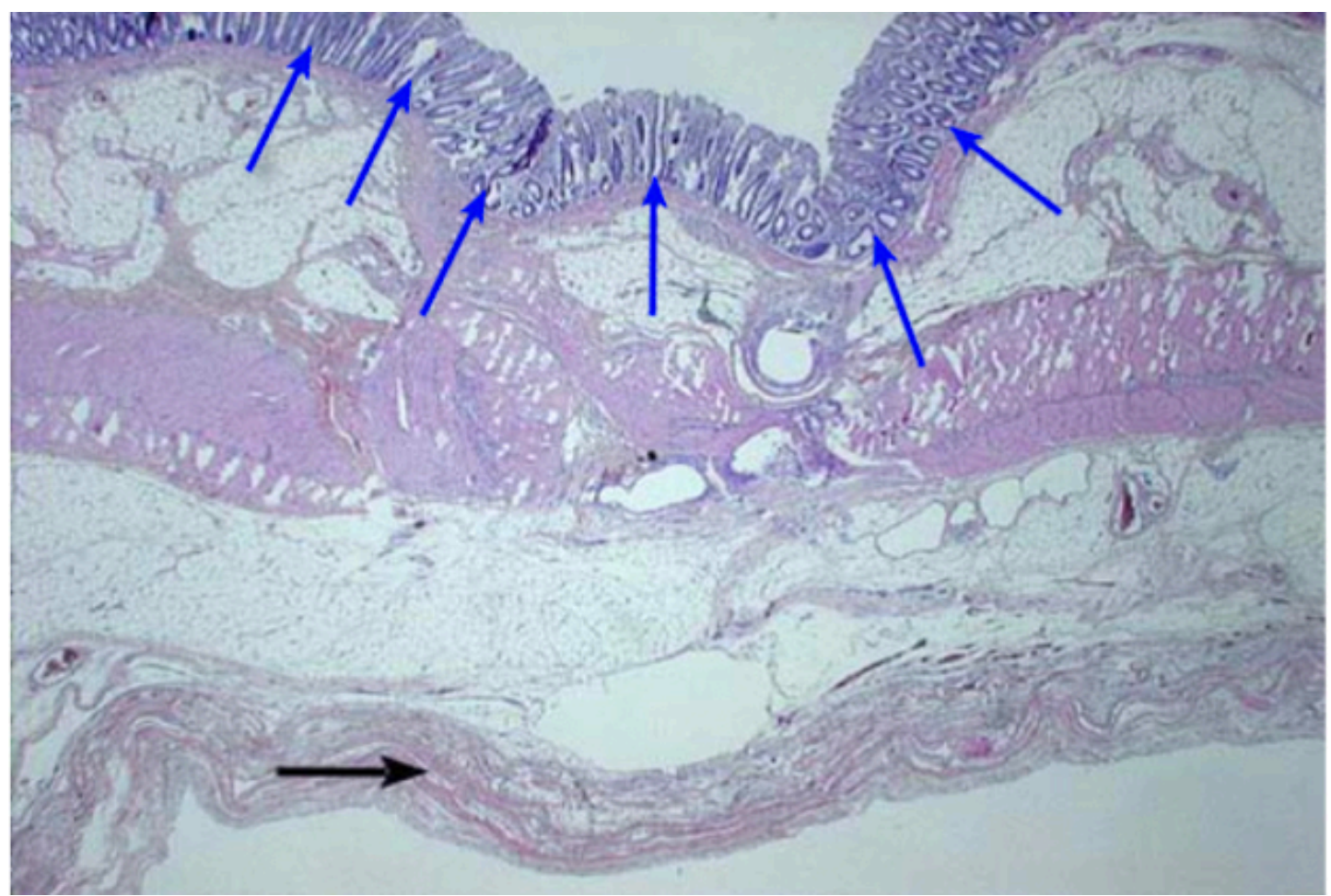

Abbildung 16: Histologische Darstellung (Hämatoxylin-Eosin-Färbung) in 10x Vergrößerung einer E/E- Descendo-Descendostomie umhüllt von SIS am 30. postoperativen Tag. Die Löcher in der Mitte sind Artefakte nach Entfernung der Metallklammern der Staplernaht. Der schwarze Pfeil deutet auf das SIS. Oben im Bild zeigen die blauen Pfeile auf die ununterbrochene Deckung der Anastomosenlinie mit Mucosa.

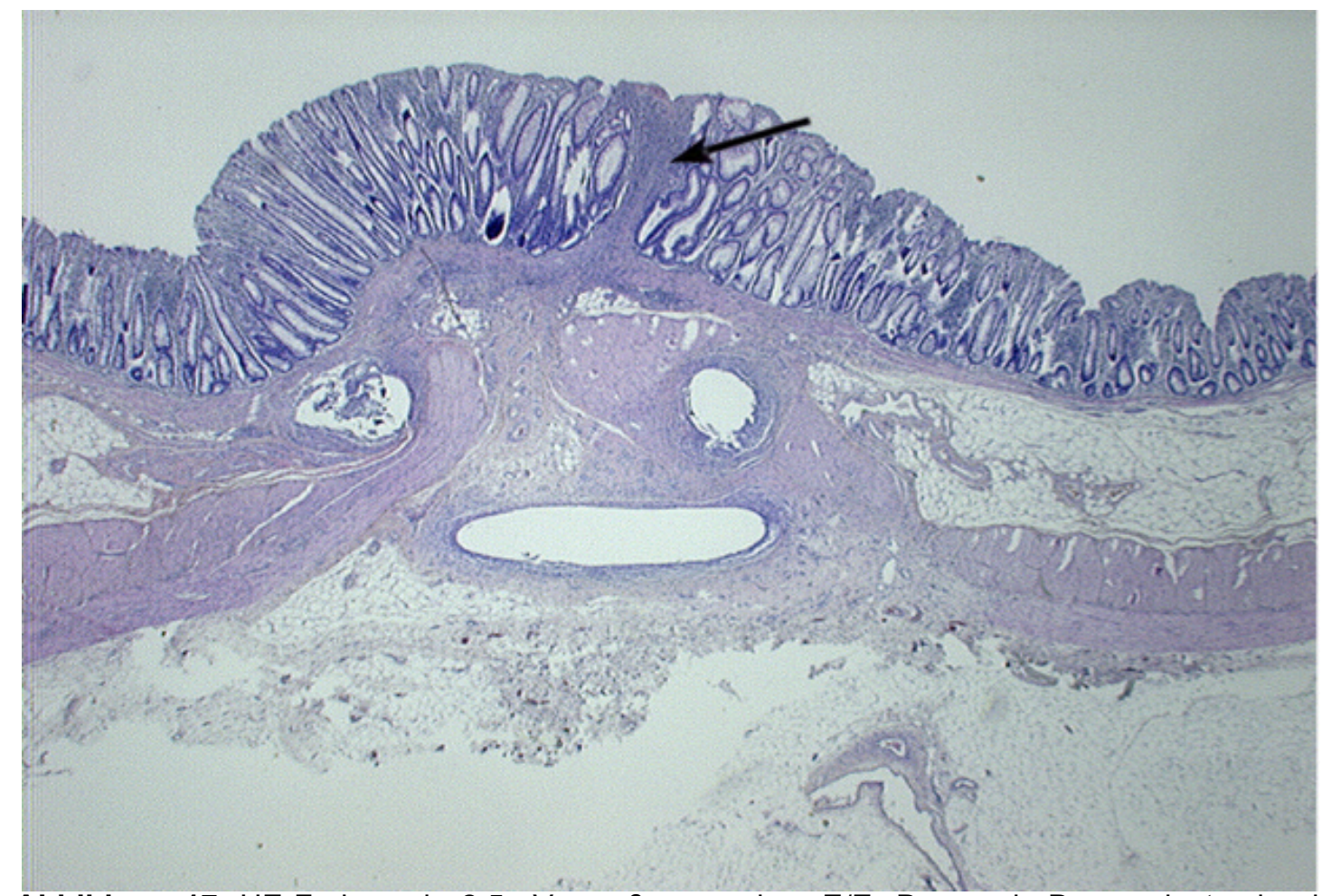

Abbildung 17: HE-Färbung in 2,5x Vergrößerung einer E/E- Descendo-Descendostomie ohne SISUmhüllung am 30. postoperativen Tag. Deutlich sichtbares Granulationsgewebe (Pfeil) entlang der Anastomosenlinie. 


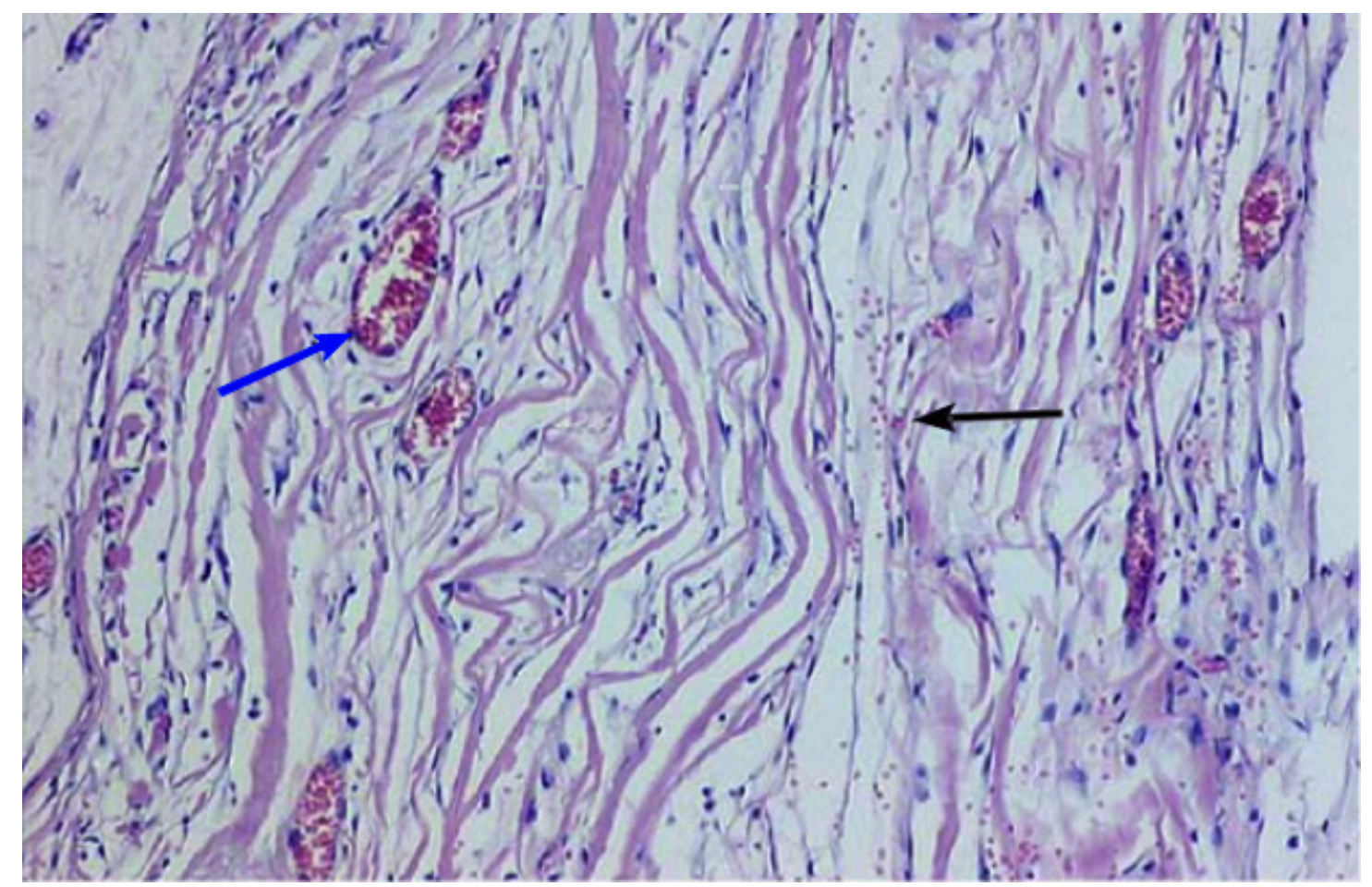

Abbildung 18: HE-Färbung 100x Vergrößerung einer Anastomose mit der Wirtsgewebeantwort auf SIS nach dem 30. postoperativen Tag (Serosaseite auf der linken und luminal zugewandte Seite auf der rechten Seite des Bildes). Der blaue Pfeil deutet auf die sichtbare Neovaskularisation (Gefäße gefüllt mit Blutzellen). Zeichen der zellulären Migration durch Lymphozyten und Makrophagen. Erkennbare aktivierte Fibroblasten (schwarzer Pfeil) im Bild.

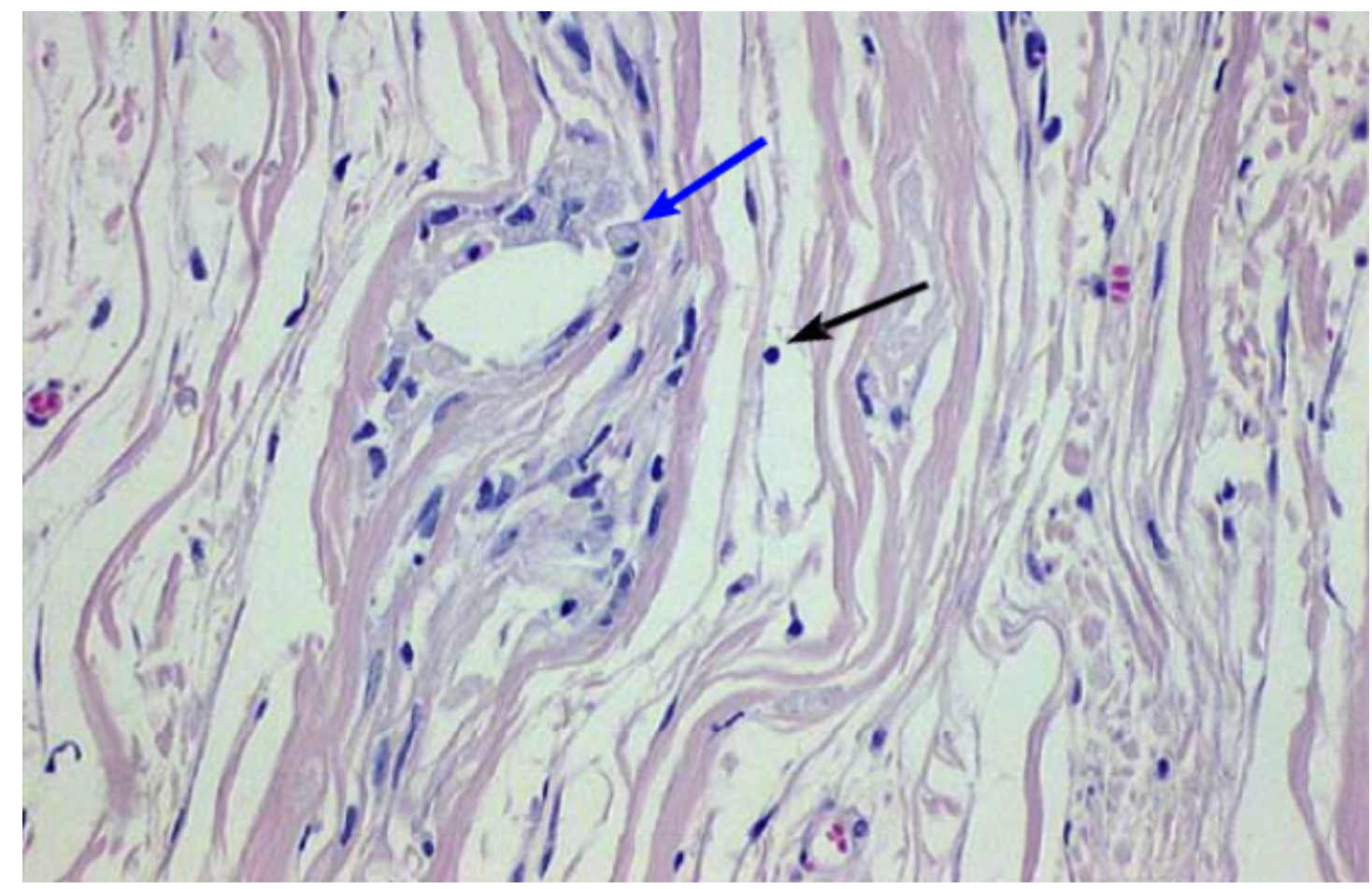

Abbildung 19: Hohe (200x) Vergrößerung einer SIS-Anastomose mit sichtbarer zellulärer Infiltration der Makrophagen (blauer Pfeil) und Lymphozyten (schwarzer Pfeil). Kleine Kapillaren sind in der Peripherie erkennbar. 


\section{Diskussion}

Physiologische Abläufe der wiederherstellenden Regenerations- und Heilungsprozesse an gastrointestinalen Hohlorganen und insbesondere deren Störungen haben eine entscheidende Relevanz für die Entwicklung von chirurgischen Risiken und Komplikationen. Durch eine gezielte Beeinflussung dieser Abläufe ist es möglich, wichtige chirurgische Krankheitsbilder in der Zukunft erfolgreicher $\mathrm{zu}$ behandeln und auch die Entwicklung lebensbedrohlicher chirurgischer Risiken und Komplikationen zu vermindern.

In dieser Arbeit wurde tierexperimentell die Wirkung der dreidimensionalen Extrazellulären Matrix SIS auf Regenerationsprozesse an gastrointestinalen Anastomosen untersucht.

In den vergangenen Jahren sind im Rahmen der experimentellen Untersuchungen von Heilungssprozessen an verschiedenen Organsystemen und Geweben Extrazelluäre Matrices (ECM), immer mehr in den Vordergrund wissenschaftlicher Untersuchungen geraten. Auf Grund ihrer ursprünglichen gastrointestinalen Herkunft ist insbesondere die aus der Submukosa des Schweinedünndarms gewonnene SIS als ECM von besonderem Interesse für Untersuchungen gastrointestinaler Heilungsprozesse. SIS ist eine der am strukturell und biochemisch genauesten charakterisierten ECM`s. Verschiedene Untersuchungen konnten bereits eine Neovaskularisation und Infiltration der Matrix mit verschiedenen wirtseigenen Zellpopulationen nachweisen (Nihsen et al. (2008), Valentin et al. (2009), Zantop et al. (2006), Badylak et al. (2002)).

In dieser Arbeit wurde der Einfluss der biologischen extrazellulären Gewebematrix SIS auf die Heilung von Dickdarmanastomosen untersucht.

Eine Verstärkung von gastrointestinalen Anastomosen durch eine umhüllende Abdichtung mit biologischen Transplantaten oder künstlichen Materialien wurde bereits in vielen unterschiedlichen Studien erforscht.

In den letzten Jahren konnten unterschiedliche Studien veröffentlicht werden, in denen gastrointestinale Anastomosen mit einem gestielten oder freien Omentumtransfer verstärkt wurden (Smith et al. (1988), Lanter und Mason (1979), Agnifili et al. (2004), Tocchi et al. (2000), Merad et al. (1998)). 
Die Untersuchungen von Lanter und Mason (1979) und Agnifili et al. (2004) beschrieben einen Benefit für die omentale Verstärkung der Anastomose mit einer Verringerung der Rate an Anastomoseninsuffizienzen. Andere Studien wiederum von Tocchi et al. (2000) und insbeondere Merad et al. (1998) konnten keinen Effekt der Omentumplastik auf die Häufigkeit von Anastomoseninsuffizienzen feststellen. Merad et al. (1998) untersuchten diesbezüglich an 712 Patienten die Inzidenzraten von Anastomoseninsuffizienzen nach kolorektalen Resektionen und Durchführung einer präventiven Omentumplastik.

Ähnlich unkonstante Ergebnisse wurden mit Studien erzielt, in denen die Anastomosen mit einem Streifen aus dem Peritoneum überzogen wurden (Gulati et al. (1982), Devine (1946), Dilek et al. (1996), Eryilmaz et al. (2007)). Weitere Studien berichten, dass die Verwendung von Dura-Mater-Plastiken zu einer Verschlechterung der Anastomosenheilung führt und zusätzlich es zu einer höheren Rate an Ausbildungen von Strikturen an den Darmwandanastomosen kommt (Eryilmaz et al. (2007)).

Neben den beschriebenen biologischen Geweben wurden auch zahlreiche synthetisch hergestellte Materialien, meistens in Einzelstudien evaluiert.

Dacron (Gulati et al. (1982)) und Polyglycolsäure-Netze (Helton et al. (2005)) zeigten keinen positiven Effekt auf die Anastomosenheilung, wohingegen die Umhüllung der Anastomosen mit Marlex Netzen die Inzidenzrate von Anastomoseninsuffizienzen verringerte (Gulati et al. (1982)). Zusammenfassend sind die Ergebnisse dieser experimentellen und klinischen Untersuchungen meistens unkonstant und nicht überzeugend genug, so dass sie eine definitive und eindeutige Aussage zum Benefit für die Anastomosenheilung und Stabilität nicht erlauben.

Einen vielversprechenden Ansatz für die Prävention von Anastomoseninsuffizienzen stellen biologische Materialien dar, die durch die Umhüllung der Anastomose diese mechanisch verstärkt und durch ihre eigene biologische Aktivität den Regenerationsprozess der Anastomosenheilung unterstützend fördert.

Es schien daher eindeutig und plausibel das SIS als Biomaterial zur möglichen Verbesserung der Anastomosenheilung zu untersuchen, welches sich bereits in der humanen klinischen Anwendung für die Hernienversorgung (Helton et al. (2005), Franklin et al. (2004)) und Behandlung von Analfisteln (Champagne et al. (2006), O'Connor et al. (2006), Schwandner et al. (2008 und 2009) Johnson et al. (2006)) befindet. 
Hodde (2002) konnte in seiner Studie nachweisen, dass SIS eine physiologische Wirtsantwort für eine Neoangiogenese und Gewebsregeneration auslöst. Zusätzlich zeigte er, dass SIS eine Remodellierung der Struktur und Funktion des an der Eingriffsstelle ursprünglichen Gewebes erzielt. Unterschiedlich verantwortliche Proteine für die zelluläre Migration und Anheftung, wie Fibronectin und Heparansulfatproteoglycan, sowie unterschiedliche Wachtumsfaktoren, wie FGF, VEGF und TGF-ß, konnten in SIS nachgewiesen werden (Hodde (2002), VoytikHarbin et al. (1997), Hodde et al. (2001)).

SIS wird für die Behandlung von Analfisteln und rektovaginalen Fistel bereits kommerziell als Plug- System (Biodesign ${ }^{\mathrm{TM}}-$ (Surgisis $^{\circledR}$ ) Fistula Plug) von der Firma Cook Biotech vertrieben. In klinischen Studien wurden für die Therapie von Analfisteln Erfolgsraten von 83\% über 2 Jahre sowie $62 \%$ über 1 Jahr berichtet (Champagne et al. (2006), Schwandner et al. (2009)). In beiden Studien konnten keine ernsthaften unerwünschten Wirkungen wie z.B. die Beeinträchtigung der Kontinenzfunktion beobachtet werden.

Das Ziel dieser Arbeit war, die Realisierbarkeit und Sicherheit der Anastomosenumhüllung mit SIS zu untersuchen. Zusätzlich sollten die makroskopischen und mikroskopischen Parameter der Anastomosenheilung und die Wirtsreaktion nach Umhüllung einer Anastomose mit SIS evaluiert werden. Nebenerscheinungen der Anwendung von SIS Patches, wie die Entstehung von Infektionen, intraabdominellen Adhäsionen oder Anastomosenstrikturen sollten ebenfalls untersucht werden.

Im Gegensatz zu anderen Materialien wie Dacron (Gulati et al. (1982)) und Polyglycolsäure-Netzen (PGA) (Henne-Bruns et al. (1990)), die für den Schutz von Anastomosen verwendet wurden, konnte wir bei den mit SIS geschützten Anastomosen keine Fisteln, Anastomosenabszesse, Peritonitis oder Anastomoseninsuffizienzen finden. Darüber hinaus fanden wir keine erhöhte Rate an Anastomosenstrikturen oder intraabdominellen Adhäsionen im Vergleich zu den Standardanastomosen. Das SIS verursachte keine relevanten luminalen Stenosen, welche für die Verwendung anderer biologischer Materialien wie Dacron, PGA und Dura Mater (Merad et al. (1998), Eryilmaz et al. (2007), Henne-Bruns et al (1990)) zur Protektion von Anastomosen beschrieben wurden. In Bezug auf Adhäsionen zeigten die anderen Materialien in ihrer Anwendung zum Schutz von Anastomosen eine relevante Erhöhung der Rate an intraabdominellen Adhäsionen (Hawley et al. 
(1970)). In unserer Studie führte das SIS zu keiner vermehrten Ausbildung von intraabdominellen Adhäsionen im Vergleich zu nicht-umhüllten StandardStapleranastomosen.

Die Anastomosenstabilität, gemessen durch die Berstungsdruckversuche, war in den SIS-geschützten Anastomosen nicht gemindert. In jedem einzelnen Berstungsdruckversuch wurden supraphysiologische intraluminale Druckwerte von $>200 \mathrm{~mm} \mathrm{Hg}$ erzielt.

Eine Einkapselung und Dislokation der umhüllenden SIS-Patches wurde in zwei von 10 Tieren in der gegenwärtigen Studie beobachtet. Ein Grund dafür könnte zum Beispiel ein frühzeitiges Aufgehen der Fixierungsnähte sein und eine darauffolgende Verziehung und Dislokation des SIS-Streifens. Eine sichtbare schrumpfende Kontraktion der umhüllenden SIS-Patches wurde in fast allen Versuchstieren der Studiengruppe gefunden.

Bei zwei Tieren bedeckte das nicht dislozierte SIS nur partiell die Zirkumferenz der Anastomose. Vermutlich würde die Verwendung von längeren SIS-Streifen als 75 $\mathrm{mm}$ mit einem größeren Überlappen der zwei SIS-Streifenenden zu einer Verringerung der Rate an partiell gedeckten Anastomosen führen. Die Sicherheit der Anastomose wurde durch diese Gegebenheit nicht vermindert. Es konnten keine Komplikationen durch die Anwesenheit von Einkapselungen, Dislokationen und Kontraktionen des SIS festgestellt werden.

Es gelang in unserem Großtiermodell, mikroskopisch die Beinflussung und Beschleunigung von Neoangiogenese, fibroblastärer Infiltration und Kollagendeposition in Kolonanastomosen nachzuweisen. Unsere Studie demonstrierte nach 30 Tagen mikroskopisch eine Migration von Fibroblasten in das SIS und zeigte eine deutliche Neovaskularisation im SIS-Patch. Bezüglich der Regeneration der Darmschichten im Anastomosenbereich war die Rate der mit Mukosa komplett gedeckten Anastomosen in der SIS-Gruppe deutlich erhöht. Die Quantität des ausgebildeten Granulationsgewebes entlang der Anastomose war ebenfalls, trotz fehlender Signifikanz in der SIS-Gruppe höher als in der Kontrollgruppe. Diese Untersuchungsergebnisse weisen auf ein Zusammenspiel zwischen dem SIS und dem Wirtsgewebe hin, welches zu einer Zytotaxis und Inkorporierung der Extrazellulären Matrix führt. Ferner scheint das SIS die Regenerationsprozesse der Darmwandschichten entlang der Anastomose zu fördern. Ungünstige Effekte wie die Ausbildung eines niedrig malignen Lymphoms in 
der Darmwandanastomose, wie sie in der Verwendung von Dacron-geschützten Anastomosen beschrieben wurden, konnten nicht gefunden werden (Gulati et al. (1982)).

Einschränkungen dieser Studie beinhalten das Fehlen von Langzeitbeobachtungen, da in unseren Untersuchungen die Darmwandanastomosen über einen Zeitraum von 30 Tagen beobachtet wurden. Andere Studienuntersuchungen berichteten, dass Schrumpfungen des SIS bei Anastomosen mit SIS-Umhüllungen langfristig Darmwandobstruktionen verursachen können (Chen und Badylak (2001), Demirbilek et al. (2003)). In Anbetracht des vollständigen Fehlens einer luminalen Einengung bei den SIS-geschützten Anastomosen nach 30 Tagen ist es äußerst unwahrscheinlich, dass das SIS Anastomosenobstruktionen über einen Beobachtungszeitraum von länger als 30 Tagen verursacht. Diese Vermutungen werden durch die Arbeit von Kini et al. (2001) bekräftigt. Er untersuchte die unterstützende Wirkung von SIS auf die Anastomosen nach laparoskopischer Anlage eines Roux-en-Y-Magenbypasses bei einer Gastrojejunostomie. In einer medianen Nachbeobachtungszeit von 87 Tagen konnte er keine signifikante Erhöhung der Stenoseraten im Vergleich zur Kontrollgruppe der Standardanastomosen feststellen. In Bezug auf die Übertragbarkeit unserer Ergebnisse auf die klinische Anwendung sind wir uns der Unterschiede zwischen der humanen und porcinen Darmheilung bewusst. Trotz dieser Einschränkungen konnte unsere Studie auf Grund der anatomischen Vergleichbarkeit im Schweinemodell nachweisen, dass es möglich und sicher ist, Kolonanastomosen mit SIS zu umhüllen, und dass es zu keinen schwerwiegenden Komplikationen im Sinne von Anastomosenobstruktionen, intraabdominellen Abszessen oder der Ausbildung von malignen Lymphomen im Anastomosenbereich kommt, wie sie in der Vergangenheit für andere biologische und künstliche Materialien, welche experimentell zur Anastomosenprotektion evaluiert worden sind, beschrieben wurden (Gulati et al. (1982), Eryilmaz et al. (2007)).

$\mathrm{Ob}$ SIS die Inzidenzrate von Anastomoseninsuffizienzen bei Menschen verringern kann, war nicht Gegenstand dieser Arbeit. Hierzu wären insbesondere weitere klinische Studien empfehlenswert und notwendig.

Auf der Grundlage der vorliegenden Studienergebnisse und in Ermangelung von suffizienten Risikomodellen in Großtieren erscheint es möglich, SIS im Rahmen von klinischen Studien an Hochrisikoanastomosen am Kolorektum vorsichtig und 
kontrolliert zu untersuchen. Insbesondere kommt hierfür zunächst eine kleine Gruppe von Patienten in Frage, bei denen es anamnestisch $\mathrm{zu}$ wiederholten Anastomoseninsuffizienzen kam, ohne dass hierfür eine bekannte und beeinflussbare Ursache zugrunde liegt.

\section{Zusammenfassung}

Anastomoseninsuffizienzen und ihre Folgen stellen ein schwerwiegendes Problem in der Viszeralchirurgie dar und führen als wesentliche Hauptkomplikation nach darmchirurgischen Operationen zu einer erhöhten Morbidität und Mortalität. Die Extrazelluläre Matrix SIS besitzt biologisch aktive Funktionen im Rahmen von Heilungsprozessen und stellt damit eine vielversprechende Methode für die Unterstützung der gastrointestinalen Anastomosenheilung dar. Das Ziel dieser Arbeit war es neben Einflüssen auf die intestinale Wundheilung, die Sicherheit und Ausführbarkeit der SIS-Umhüllung in einem mit dem Menschen anatomisch vergleichbaren Tiermodell zu untersuchen. Im Rahmen dieser Studie wurde die SISUmhüllung an zirkulären Stapleranastomosen im Schweinemodell untersucht. Insgesamt 18 Schweine wurden in 2 Gruppen randomisiert. In der Kontrollgruppe wurde eine einfache End-zu-End-Descendo-Descendostomie als zirkuläre Stapleranastomose angelegt. Die Tiere der Studiengruppe erhielten im Vergleich zusätzlich eine zirkuläre Umhüllung der Stapleranastomose mit einem 75×25 mm messenden SIS-Patch. Der Beobachtungszeitraum beider Gruppen betrug 30 Tage. Am Versuchsende wurde das Anastomosensegment entnommen und zunächst eine Röngtenkontrastdarstellung des Anastomosenlumens durchgeführt. Im Anschluss wurde der Berstungsdruck gemessen und das Präparat makroskopisch und mikroskopisch inspiziert. Anastomoseninsuffizienzen wurden in keinem Tier innerhalb beider Studiengruppen beobachtet. Es zeigten sich keine relevanten luminalen Einengungen. Es konnten keine signifikanten Unterschiede der mechanischen Belastbarkeit der Anastomosen zwischen SIS-umhüllten Anastomosen und Standardanastomosen festgestellt werden. Die makroskopischen Untersuchungen zeigten in beiden Untersuchungsgruppen keine intraabdominellen Abszesse, Fisteln, oder Nekrosen entlang der Anastomose. Innerhalb der beiden Versuchsgruppen konnten keine signifikanten Unterschiede im Überleben der Tiere gefunden werden. Mikroskopisch konnte eine gesteigerte Neovaskularisation sowie 
Einsprossung von Fibroblasten und Makrophagen in den Anastomosenbereich der SIS-umhüllten Anastomosen beobachtet werden. Weiterhin zeigten sich histologisch Hinweise für eine verbesserte Anastomosenheilung mit einem höheren Anteil der komplett mit Mukosa gedeckten Anastomosen sowie einer gesteigerten Quantität von Granulationsgewebe in der SIS-Gruppe, ohne allerdings ein signifikantes Niveau zu erreichen.

Es konnte in dieser Arbeit, in einem mit dem Menschen anatomisch vergleichbaren Modell gezeigt werden, dass es möglich und sicher ist, Kolonanastomosen mit SIS zu umhüllen, ohne dass es dabei zu schwerwiegenden Komplikationen im Sinne von Anastomosenobstruktionen, intraabdominellen Abszessen oder der Ausbildung von Lymphomen im Anastomosenbereich kommt. 


\section{Anhang}

\subsection{Abkürzungsverzeichnis}

\% Prozent

Abb. Abbildung

Al Anastomosenindex

bFGF basic-Fibroblast-Growth-Factor

Bioscaffold biologisches Gerüst

CEEA zirkuläre End-zu-End Anastomose

Ch Charrier

$\mathrm{cm} \quad$ Zentimeter

ECM Extrazelluläre Matrix (Matrices)

E/E End-zu-End

et al. et alii

Fa. Firma

FGF-2 Fibroblast Growth Factor-2

GIT Gastrointestinal-Trakt

HE Hämatoxylin-Eosin

i.v intravenös

IAD intraabdomineller Druck

kg Kilogramm

kgKG Kilogramm Körpergewicht

$\min \quad$ Minute

$\mathrm{ml} \quad$ Milliliter

$\mathrm{mm} \quad$ Millimeter

$\mathrm{mmHg} \quad$ Millimeter Quecksilbersäule

MMP Matrix-Metallproteinase

um Mikrometer

n Anzahl

$\mathrm{NIH} \quad$ National Institutes of Health

Nr. Nummer

ns nicht signifikant

OP Operation 


$\begin{array}{ll}\text { Patch } & \text { Streifen } \\ \text { PDGF } & \text { Platelet-derived-growth-factor } \\ \text { PGA } & \text { Polyglycolsäure } \\ \text { porcin } & \text { vom Schwein stammend } \\ \text { p-Wert } & \text { Irrtumswahrscheinlichkeit } \\ \text { Remodeling } & \text { Umformung, Umbauvorgang } \\ \text { SEM } & \text { standard error of the mean } \\ \text { SIS } & \text { Small Intestinal Submucosa } \\ \text { Tab. } & \text { Tabelle } \\ \text { TGF-1 } & \text { Transforming Growth Factor-1 } \\ \text { TGF- } ß & \text { Transforming Growth Factor- } ß \\ \text { TIMP } & \text { Tissue-inhibitor-matrix-metalloproteinase } \\ \text { v.a } & \text { vor allem } \\ \text { VEGF } & \text { Vascular-Endothelial Growth Factor } \\ \text { vs. } & \text { versus } \\ \text { z.B. } & \text { zum Beispiel }\end{array}$




\subsection{Literaturverzeichnis}

1. Abramowitz H B, McAlister W H (1969): A comparative study of small-bowel anastomoses by angiography and microangiography. Surgery $\underline{66}$ : 564-569

2. Aderem A (2003): Phagocytosis and the inflammatory response. J Infect Dis Suppl 2: S340-345

3. Agnifili A, Schietroma M, Carloni A, Mattucci S, Caterino G, Lygidakis N J (2004): The value of omentoplasty in protecting colorectal anastomosis from leakage. A prospective randomized study in 126 patients. Hepatogastroenterology 51: 16941697

4. Akyol A M, McGregor J R, Galloway D J, George W D (1992): Early

postoperativecontrast radiology in the assessment of colorectal anastomotic integrity. Int J Colorectal Dis ㅍ: 141-143

5. Alberts J C J, Parvaiz A, Moran B J (2003): Predicting risk and diminishing the consequences of anastomotic dehiscence following rectal resection. Colorectal Dis 5: 478-82

6. Andersen E, Sondenaa K, Holter J (1989): Acomparative study of polydioxanone (PDS) and polyglactin 910 (Vicryl) in colonic anastomoses in rats. Int J Colorectal Dis 4: $251-254$

7. Ansaloni L, Bonasoni P, Cambrini P, Catena F, De Cataldis A, Gagliardi S, Gazzotti F, Peruzzi S, Santini D, Taffurelli M (2006): Experimental evaluation of Surgisis as scaffold for neointestine regeneration in a rat model. Transplant Proc $\underline{38}$ : 1844-1848

8. Badylak S F, Lantz G C, Coffey A, Geddes L A (1989): Small intestinal submucosa as a large diameter vascular graft in the dog. J Surg Res $\underline{47}: 74-80$ 
9. Badylak S, Meurling S, Chen M, Spievack A, Simmons-Byrd A(2000): Resorbable bioscaffold for esophageal repair in a dog model. J Pediatr Surg $\underline{35}$ : 1097-1103

10. Badylak S, Kokini K, Tullius B, Simmons-Byrd A, Morff R (2002): Morphologic study of small intestinal submucosa as a body wall repair device. J Surg Res $\underline{103}$ : 190-202

11. Bissell M J, Aggeler J (1987): Dynamic reciprocity: how do extracellular matrix and hormones direct gene expression. Prog Clin Biol Res 249: 251-62

12. Bokey E L, Chapuis P H, Fung C, Hughes W J, Koorey S G, Brewer D, Newland R C (1995): Postoperative morbidity and mortality following resection of the colon and rectum for cancer. Dis Colon Rectum May $\underline{38}$ : 480-486 discussion 486-7

13. Boschung $U$ (2003): Milestones in the history of intestinal anastomosis. Swiss Surg 9: 99-104

14. Briel J W, Tamhankar A P, Hagen J A, DeMeester S R, Johansson J, Choustoulakis E, Peters J H, Bremner C G, DeMeester T R (2004): Prevalence and risk factors for ischemia, eak, and stricture of esophageal anastomosis: gastric pull-up versus colon interposition. J Am Coll Surg 198: 536-541 discussion 541-532

15. Brown E, Dejana E, editors (2003): Cell-to-cell contact and extracellular matrix editorial overview: cell-cell and cell-matrix interactions-running, jumping, standing still. Curr Opin Cell Biol 15: 1-4

16. Bucher $\mathrm{O}$, Wartenberg $\mathrm{H}$ Cytologie, Histologie und mikroskopische Anatomie des Menschen. 11. Auflage Verlag Hans Huber, Bern 1989

17. Buchs N C, Gervaz P, Secic M, Bucher P, Mugnier-Konrad B, Morel P (2007): Incidence, consequences, and risk factors for anastomotic dehiscence after colorectal surgery: a prospective monocentric study. Int J Colorectal Dis 23: 265-70 
18. Champagne B J, O'Connor L M, Ferguson M, Orangio G R, Schertzer M E, Armstrong D N (2006): Efficacy of anal fistula plug in closure of cryptoglandular fistulas: long-term follow-up. Dis Colon Rectum 49: 1817-1821

19. Charrier L, Yan Y, Driss A, Laboisse C L, Sitaraman S L, Merlin D (2004): ADAM15 inhibits wound healing in human intestinal epithelial cell monolayers. Am Physiol Gastrointest Liver Physiol 288: 346-353

20. Chen M K, Badylak S F (2001): Small bowel tissue engineering using small intestinal submucosa as a scaffold. J Surg Res $\underline{99}$ : 352-358

21. Choi H K, Law W L, Ho J W (2006): Leakage after resection and intraperitoneal anastomosis for colorectal malignancy: analysis of risk factors. Dis Colon Rectum $\underline{49}$ : $1719-25$

22. Chowcat N L, Savage F J, Lewin M R, Boulos P B (1990): Direct measurement of collagenase in colonic anastomosis. Br J Surg $\underline{77}$ : 1284-7

23. Cronin K, Jackson D S, Dunphy J E (1968): Specific activity of hydroxyproline-tritium in the healing colon. Surg Gynecol Obstet 126: 1061-1065

24. Debas H T, Thomson F B (1972): A critical review of colectomy with anastomosis. Surg Gynecol Obstet 135: 747-752

25. De la Fuente S G, Gottfried M R, Lawson D C, Harris M B, Mantyh C R, Pappas T N (2003): Evaluation of porcine-derived small intestine submucosa as a biodegradable graft for gastrointestinal healing. J Gastrointest Surg 7: 96-101

26. Demirbilek S, Kanmaz T, Ozardali I, Edali M N, Yucesan S (2003): Using porcine small intestinal submucosa in intestinal regeneration. Pediatr Surg Int 19: 588-592

27. De Ugarte D A, Choi E, Weitzbuch H, Wulur I, Caulkins C, Wu B, Fonkalsrud E W, Atkinson J B, Dunn J C (2004): Mucosal regeneration of a duodenal defect using small intestine submucosa. Am Surg 70: 49-51 
28. Devine J (1946): Preliminary report of a method for prevention of leakage of intestinal anastomosis: an experimental study. Surg Gynaecol Obstet 82: 475

29. Dilek O N, Bakir B, Dilek F H, Demirel H, Yiğit M F (1996): Protection of intestinal anastomoses in septic environment with peritoneal graft and polyglycolic acid mesh: an experimental study. Acta Chir Belg 96: 261-265

30. Eryilmaz R, Samuk M, Tortum O B, Akcakaya A, Sahin M, Goksel S (2007): The role of dura mater and free peritoneal graft in the reinforcement of colon anastomosis. J Invest Surg 20 : 15-21

31. Fa. Greisinger, Regenstauf, Deutschland

32. Foster M E, Laycock J R, Silver I A, Leaper D J (1985): Hypovolaemia and healing in colonic anastomoses. $\mathrm{Br} \mathrm{J}$ Surg $\underline{72}$ : 831-834

33. Franken M, Influence of controlled zinc deficiency on proteinexpression during wound healing in intestinal anastomosis of rats. Med. Diss. RWTH Aachen 2010

34. Franklin M E Jr, Gonzalez J J Jr, Glass J L (2004): Use of porcine small intestinal submucosa as a prosthetic device for laparoscopic repair of hernias in contaminated fields: 2-year follow-up. Hernia Epub $\underline{8}$ : 186-189

35. Gailit J, Clark R A F (1994): Wound repair in the context of extracellular matrix. Curr Opin Cell Biol $\underline{6}:$ 717-725

36. Girgin S, Gedik E, Ozturk H, Akpolat V, Kale E, Buyukbayram H, Celik S (2009): Effects of combined pulse electromagnetic field stimulation plus glutamine on the healing of colonic anastomosis in rats. Dig Dis Sci $\underline{54}$ : 745-50

37. Goligher J C, Lee P W, Simpkins K C, Lintott D J (1977): A controlled comparison one-and two-layer techniques of suture for high and low colorectal anastomoses. $\mathrm{Br} \mathrm{J}$ Surg 64: 609-614 
38. Gomez D E, Alonso D F, Yoshiji H, Thorgeirsson U P (1997): Tissue Inhibitors of Metalloproteinases: Structure, Regulation and biological function. Eur J Cell Biol 74: 111-22

39. Graf W, Glimelius B, Bergstrom R, Pahlman L (1991): Complications after double and single stapling in rectal surgery. Eur J Surg 157: 543-547

40. Graham M F, Drucker D E, Diegelmann R F, Elson C O (1987): Collagen synthesis by human intestinal smooth muscle cells in culture. Gastroenterology 92: 400-405

41. Greiling D, Clark R A (1997): Fibronectin provides a conduit for fibroblast transmigration from collagenous stroma into fibrin clot provisional matrix. J Cell Sci 110: $861-870$

42. Grinnell F, Toda K, Takashima A (1987): Activation of keratinocyte fibronectin receptor function during cutaneous wound healing. J Cell Sci Suppl $\underline{8}:$ 199-209

43. Guide for Care and Use of Laboratory Animals ( NIH Publikation Nr. 86-23 ), NIH Bethesda 1985

44. Gulati S M, Thusoo T K, Kakar A, lyenger B, Pandey K K (1982): Comparative study of free omental, peritoneal, Dacron velour, and Marlex mesh reinforcement of large-bowel anastomosis: an experimental study. Dis Colon Rectum 25: 517-521

45. Halsted W S (1887): Circular suture of the intestine: an experimental study. Am J Med Sci 94: 43-46

46. Hartmann M, Jonsson K, Zederfeldt B (1992): Importance of dehydration in anastomotic and subcutaneous wound healing: an experimental study in rats. Eur $\mathrm{J}$ Surg 158: 79-82 
47. Hawley P R, Faulk W P, Hunt T K, Dunphy J E (1970): Collagenase activity in the gastro intestinal tract. Br J Surg 57: 896-900

48. Helton W S, Fisichella P M, Berger R, Horgan S, Espat N J, Abcarian H (2005): Short-term outcomes with small intestinal submucosa for ventral abdominal hernia. Arch Surg 140: 549-560 discussion 560-2

49. Hendriks T, Vereecken T H, Hesp W L, Schillings P H, de Boer H H (1985): Loss of collagen from experimental intestinal anastomoses: early events. Exp Mol Pathol 42: $411-418$

50. Henne-Bruns D, Kreischer H P, Schmiegelow P, Kremer B (1990): Reinforcement of colon anastomoses with polyglycolic acid mesh: an experimental study. Eur Surg Res 22: 224-230

51. Hesp W L, Lubbers E J, de Boer H H, Hendriks T (1986): Anastomotic insufficiency in small bowel surgery-incidence and treatment. Langenbecks Arch Chir 368: $105-111$

52. Hodde J (2002): Naturally occurring scaffolds for soft tissue repair and regeneration. Tissue Eng $\underline{8}$ : 295-308

53. Hodde J P, Record R D, Liang H A, Badylak S F (2001): Vascular endothelial growth factor in porcine-derived extracellular matrix. Endothelium $\underline{8}$ : 11-24

54. Hu Y, Guimond S E, Travers P, Cadman S, Hohenester E, Turnbull J E, Kim S H, Bouloux P M (2009): Novel mechanisms of fibroblast growth factor receptor 1 regulation by extracellular matrix protein anosmin-1. J Biol Chem 284: 29905-20

55. Irvin T T (1978): Effects of malnutrition and hyperalimentation on wound healing. Surg Gynecol Obstet 146: 33-37.

56. Jahnson S, Holtz A, Gerdin B (1998): Anastomotic blood-flow reduction in rat small intestine with chronic radiation damage. Digestion 59: 134-141 
57. Jansson O K, Zilling T L, Walther B S (1991): Healing of colonic anastomoses: comparative experimental study of glued, manually sutured, and stapled anastomoses.Dis Colon Rectum 34: 557-562

58. Johnson E K, Gaw J U, Armstrong D N (2006): Efficacy of anal fistula plug vs. fibrin glue in closure of anorectal fistulas. Dis Colon Rectum 49: 371-376

59. Jonsson T, Hogstrom $H$ (1992): Effect of suture technique on early healing of intestinal anastomoses in rats. Eur J Surg 158: 267-270

60. Joshi G P (2005): Intraoperative fluid restriction improves outcome after major elective gastrointestinal surgery. Anesth Analg 101: 601-605

61. Junqueira, Carneiro, Histologie 3. Auflage Springer-Verlag Berlin Heidelberg 1991

62. Kaemmer D A, Otto J, Binneboesel M, Klink C, Krones C, Jansen M, Cloer C, Oettinger A, Schumpelick V, Klinge U (2010): Erythropoietin (EPO) influences colonic anastomotic healing in a rat model by modulating collagen metabolism. J Surg Res 163: $67-72$

63. Kini S, Gagner M, de Csepel J, Gentileschi P, Dakin G (2001): A biodegradable membrane from porcine intestinal submucosa to reinforce the gastrojejunostomy in laparoscopic Roux-en-Y gastric bypass: preliminary report. Obes Surg 11: 469-473

64. Kleinman H K, Philp D, Hoffman M P (2003): Role of the extracellular matrix in morphogenesis. Curr Opin Biotechnol 14: 526-32

65. Kochupura P V, Azeloglu E U, Kelly D J, Doronin S V, Badylak S F, Krukenkamp I B, Cohen I S, Gaudette G R (2005): Tissue-engineered myocardial patch derived from extracellular matrix provides regional mechanical function. Circulation 112: I1449 
66. Konishi T, Watanabe T, Kishimoto J, et al. (2006): Risk factors for anastomotic leakage after surgery for colorectal cancer: results of prospective surveillance. J Am Coll Surg 202: 439-444

67. Kropp B P, Rippy M K, Badylak S F, Adams M C, Keating M A, Rink R C, Thor K B (1996): Regenerative urinary bladder augmen- tation using small intestinal submucosa: urodynamic and histopathologic assessment in long-term canine bladder augmentations. J Urol 155: 2098-2104

68. Kubo K, Kuroyanagi Y (2003): Spongy matrix of hyaluronic acid and collagen as a cultured dermal substitute: evaluation in an animal test. J Artif Organs $\underline{6}$ : 64-70

69. Lanter B, Mason R A (1979): Use of omental pedicle graft to protect low anterior colonic anastomosis. Dis Colon Rectum 22: 448-451

70. Law W L, Chu K W (2004): Anterior resection for rectal cancer with mesorectal excision: a prospective evaluation of 622 patients. Ann Surg 240: 260-268

71. Ljungqvist O, Soreide E (2003): Preoperative fasting. Br J Surg 90: 400-406

72. Lobo D N, Bostock K A, Neal K R, Perkins A C, Rowlands B J, Allison S P (2002): Effect of saltand water balance on recovery of gastrointestinal function after elective colonic resection: a randomised controlled trial. Lancet $\underline{359}$ : 1812-1818.

73. Lobo D N, Macafee D A, Allison S P (2006): How perioperative fluid balance influences postoperative outcomes. Best Pract Res Clin Anaesthesiol 20: 439-455

74. Lodish H, Berk A, Kaiser C A, Krieger M, Scott M P, Bretscher A, Ploegh H, Matsudeira P. Molecular Cell Biology. Sixth Edition. W H Freeman and Company, New York 2008

75. Lopes M F, Cabrita A, Ilharco J, Pessa P, Patrício J (2006): Grafts of porcine intestinal submucosa for repair of cervical and abdominal esophageal defects in the rat. J Invest Surg 19: 105-111 
76. Lorentz T, Fok M, Wong J (1989): Anastomotic leakage after resection and bypass for esophageal cancer: lessons learned from the past. World J Surg 13: 472-477

77. Makela J T, Kiviniemi H, Laitinen S (2003): Risk factors for anastomotic leakage after left-sided colorectal resection with rectal anastomosis. Dis Colon Rectum $\underline{46}$ : $653-60$

78. Mann B, Kleinschmidt S, Stremmel W (1996): Prospective study of hand-sutured anastomosis after colorectal resection. Br J Surg 우: 29-31

79. Marescaux J F, Aprahamian M, Mutter D, Loza E, Wilhelm M, Sonzini P, Damge C (1991): Prevention of anastomosis leakage: an artificial connective tissue. $\mathrm{Br} \mathrm{J}$ Surg 78: $440-444$

80. Marjanovic G., Schrag H J, Fischer E, Hopt U T, Fischer A (2008): Endoscopic bougienage of benign anastomotic strictures in patients after esophageal resection: the effect of the extent of stricture on bougienage results. Dis Esophagus 21: $551-557$

81. Martens M F, Hendriks T (1991): Postoperative changes in collagen synthesis in intestinal anastomoses of the rat: differences between small and large bowel. Gut $\underline{32}$ : 1482-1487.

82. Martens M F, Huyben C M, Hendriks T (1992): Collagen synthesis in fibroblasts from human colon: regulatory aspects and differences with skin fibroblasts. Gut $\underline{33}$ : 1664-1670

83. Mast B A (1997): Healing in other tissues. Surg Clin North Am 77: 529-547

84. Mastboom W J (1991): The influence of NSAID's on experimental intestinal anastomosis. Dis Col Rec 34: 236-43 
85. Matthiessen P, Hallböök O, Andersson M, Rutegård J, Sjödahl R (2004): Risk factors for anastomotic leakage after anterior resection of the rectum. Colorectal Dis 6: $462-9$

86. Merad F, Hay J M, Fingerhut A, Flamant Y, Molkhou J M, Laborde $Y$ (1998): Omentoplasty in the prevention of anastomotic leakage after colonic or rectal resection: a prospective randomized study in 712 patients. Ann Surg 227: 179-186

87. Meyer T, Chodnewska I, Czub S, Hamelmann W, Beutner U, Otto C, Thiede A, Ulrichs K (1998): Extracellular matrix proteins in the porcine pancreas: a structural analysis for directed pancreatic islet isolation. Transplant Proc 30: 354

88. Moore K (1999): Cell biology of chronic wounds: the role of inflammation. J Wound Care 8: $345-348$

89. Nahai F, Lamb J M, Havican R G, Stone H H (1977): Factors involved in disruption of intestinal anastomoses. Am Surg 43: 45-51

90. Nesbakken A, Nygaard K, Lunde O C (2001): Outcome and late functional results after anastomotic leakage following mesorectal excision for rectal cancer. $\mathrm{Br} \mathrm{J}$ Surg 88: 400-404

91. Netta S, Michalopoulos A, Apostolidis S, Paramythiotis D, Papavramidis T, Papadopoulos V, Tziris N (2010): Enhancement of colonic anastomotic strength in rats by short-chain fatty acids. Tech Coloproctol 14 : S53-5

92. Neutzling C B, Lustosa S A, Proenca I M, da Silva E M, Matos D (2012): Stapled versus handsewn methods for colorectal anastomosis surgery. Cochrane Database Syst Rev 2: CD003144

93. Nickelsen $T$ N, Jorgensen $T$, Kronborg $O$ (2005): Lifestyle and 30-day complications to surgery for colorectal cancer. Acta Oncol $\underline{44}$ : 218-23 
94. Nihsen E S, Johnson C E, Hiles M C (2008): Bioactivity of small intestinal submucosa and oxidized regenerated cellulose/collagen. Adv Skin Wound Care 21: 479-86

95. O'Connor L, Champagne B J, Ferguson M A, Orangio G R, Schertzer M E, Armstrong D N (2006): Efficacy of anal fistula plug in closure of Crohn's anorectal fistulas. Dis Colon Rectum 49: 1569 - 1573

96. Pahari M P, Raman A, Bloomenthal A, Costa M A, Bradley S P, Banner B, Rastellini C, Cicalese L (2006): A novel approach for intestinal elongation using acellular dermal matrix: an experimental study in rats. Transplant Proc $\underline{38}$ : 1849-1850

97. Pakkastie T E, Luukkonen P E, Jarvinen H J (1994): Anastomotic leakage after anteriorresectio of the rectum. Eur J Surg 160: 293-297 discussion 299-300

98. Pellegrini L (2001): Role of heparan sulfate in fibroblast growth factor signalling: a structural view.Curr Opin Struct Biol 11: 629-34

99. Petersen S, Freitag M, Hellmich G, Ludwig K (1998): Anastomotic leakage: impact on local recurrence and survival in surgery of colorectal cancer. Int $\mathrm{J}$ Colorectal Dis 13: 160- 163

100. Phillips J D, Kim C S, Fonkalsrud E W, Zeng H, Dindar H (1992): Effects of chronic corticosteroids and vitamin $\mathrm{A}$ on the healing of intestinal anastomoses. Am J Surg 163: 71-7

101. Polat A, Nayci A, Polat G, Aksoyek S (2002): Dexamethasone down-regulates endothelial expression of intercellular adhesion molecule and impairs the healing of bowel anastomoses. Eur J Surg 168: 500-506

102. Pschyrembel Klinisches Wörterbuch, 263. Auflage, de Gruyter, Berlin, New York 2011 
103. Rhagow $R$ (1994): The role oft extracellular matrix in postinflammatory wound healing and fibrosis. FASEB (Fed Am Soc Exp Biol) J 8 : 823-831

104. Ringsdorf W M Jr, Cheraskin E (1982): Vitamin C and human wound healing. Oral Surg Oral Med Oral Pathol $\underline{53}:$ 231-236

105. Rosen M, Ponsky J, Petras R, Fanning A, Brody F, Duperier F (2002): Small intestinal submucosa as bioscaffold for biliary tract regeneration. Surgery 132: 480 486

106. Rosso F, Giordano A, Barbarisi M, Barbarisi A (2004): From cell-ECM interactions to tissue engineering. J Cell Physiol 199: 174-80

107. Rullier E, Laurent C, Garrelon J L, Michel P, Saric J, Parneix M (1998): Risk factors for anastomotic leakage after resection of rectal cancer. $\mathrm{Br} \mathrm{J}$ Surg $\underline{85}$ : 355-358

108. Sarin S, Lightwood R G (1989): Continuous single-layer gastrointestinal anastomosis: a prospective audit. Br J Surg $\underline{76}$ : 493-495

109. Schrock T R, Deveney C W, Dunphy J E (1973): Factor contributing to leakage of colonicanastomoses. Ann Surg 177: 513-518

110. Schwandner O, Stadler F, Dietl O, Wirsching R P, Fuerst A (2008): Initial experience on efficacy in closure of cryptoglandular and Crohn's transsphincteric fistulas by the use of the anal fistula plug. Int J Colorectal Dis $\underline{23}$ : 319-324

111. Schwandner T, Roblick M H, Kierer W, Brom A, Padberg W, Hirschburger M (2009): Surgical treatment of complex anal fistulas with the anal fistula plug: a prospective, multicenter study. Dis Colon Rectum 52: 1578-83

112. Seifert W F, Wobbes $T$, Hoogenhout $J$, de Man B M, Huyben K M, Hendriks $T$ (1995): Intraoperative irradiation delays anastomotic repair in rat colon. Am J Surg 170: 256- 261 
113. Smith S R, Swift I, Gompertz H, Baker W N (1988): Abdomino- perineal and anterior resection of the rectum with retrocolic omentoplasty and no drainage. $\mathrm{Br} \mathrm{J}$ Surg 75: 1012-1015

114. Soeters P B, De Zoete J P, Dejong C H, Williams N S, Baeten C G (2002): Colorectal surgery and anastomotic leakage. Dig Surg 19: 150-155

115. Sørensen L T, Jørgensen T, Kirkeby L T, Skovdal J, Vennits B, Wille-Jørgensen $P$ (1999): Smoking and alcohol abuse are major risk factors for anastomotic leakage in colorectal surgery. Br J Surg $\underline{86}$ : 927-31

116. Souza Filho Z A, Greca F H, Rocha S L, loshii S O, Domanski A C, Kfouri D, Campos P D, Silva R F (2005): Porcine submucosa graft for the treatment of duodenal injuries in dogs. Acta Cir Bras 20: 394-398

117. Stelzner F (1982): Prevention of intraperitoneal suture insufficiency (small and large intestine). Langenbecks Arch Chir $\underline{358}$ : 259-263

118. Stumpf M, Cao W, Klinge U, Klosterhalfen B, Kasperk R, Schumpelick V (2002): Collagen distribution and expression of matrix metalloproteinases 1 and 13 in patients with anastomotic leakage after large-bowel surgery. Langenbecks Arch Surg 386: 502-506

119. Stumpf M, Klinge U, Mertens P R (2004): Anastomosenheilung - Prognostische Faktoren. Der Chirurg 75: 1056-1062

120. Surgisis R, Cook Surgical, Lafayette, IN, USA, URL: http://www. cookbiotech.com. 2010

121. Tadros $T$, Wobbes $T$, Hendriks $T$ (1992): Blood transfusion impairs the healing of experimental intestinal anastomoses. Ann Surg 215: 276-281

122. Thompson S K, Chang E Y, Jobe B A (2006): Clinical review: Healing in gastrointestinal anastomoses, part I. Microsurgery $\underline{26}$ : 131-136 
123. Thornton F J, Barbul A (1997): Healing in the gastrointestinal tract. Surg Clin North Am 77: 549-573

124. Tireli G A, Salman T, Ozbey H, Abbasoglu L, Toker G, Celik A (2003): The effect of pentoxifylline on intestinal anastomotic healing after ischemia. Pediatr Surg Int 19: 88-90

125. Tocchi A, Mazzoni G, Lepre L, Costa G, Liotta G, Agostini N (2000): Prospective evaluation of omentoplasty in preventing leakage of colorectal anastomosis. Dis Colon Rectum 43: 951- 955

126. Tomasek J J, Gabbiani G, Hinz B, Chaponnier C, Brown R A (2002): Myofibroblasts and mechano-regulation of connective tissue remodelling. Nat Rev Mol Cell Biol $\underline{3}$ : 349-363

127. Tsirogianni A K, Moutsopoulos N M, Moutsopoulos H M (2006): Wound healing: immunological aspects. Injury $\underline{37}$ : S5-12

128. Ueno T, Oga A, Takahashi T, Pappas T N (2007a): Small intestinal submucosa (SIS) in the repair of a cecal wound in unprepared bowel in rats. J Gastrointest Surg 11: $918-922$

129. Ueno T, de la Fuente S G, Abdel-Wahab O I, Takahashi T, Gottfried M, Harris M B, Tatewaki M, Uemura K, Lawson D C, Mantyh C R, Pappas T N (2007b): Functional evaluation of the grafted wall with porcine-derived small intestinal submucosa (SIS) to a stomach defect in rats. Surgery 142: $376-383$

130. Universität Bielefeld, Sonderforschungsbereich 549, URL: http://www.unibielefeld.de/SFB549/. 2005

131. Ustek S, Kismet K, Akkus M A, Ozcan A H, Aydogan A, Renda N (2005): Effect of povidone- iodine liposome hydrogel on colonic anastomosis. Eur Surg Res $\underline{37}$ : 242-5 
132. Valentin J E, Stewart-Akers A M, Gilbert T W, Badylak S F (2009): Macrophage participation in the degradation and remodeling of extracellular matrix scaffolds. Tissue Eng Part A 15:1687-94

133. Vandertoll D J, Beahrs O H (1965): Carcinoma of Rectum and Low Sigmoid; Evaluation of Anterior Resection of 1,766 Favorable Lesions. Arch Surg 90: 793-798

134. Verlag: webop GmbH, Köln (www.webop.de)

135. Voytik-Harbin S L, Brightman A O, Kraine M R, Waisner B, Badylak S F (1997): Identification of extractable growth factors from small intestinal submucosa. J Cell Biochem 67: 478-491

136. Wang Z Q, Watanabe $Y$, Noda T, Yoshida A, Oyama T, Toki A (2005): Morphologic evaluation of regenerated small bowel by small intestinal submucosa. $J$ Pediatr Surg 40: 1898-1902.

137. Waninger J, Kaufmann G W, Shah I A, Farthman E H (1992): Influence of the distance between interrupted sutures and the tension of sutures on the healing of experimental colonic anastomoses. Am J Surg 163: 319-323

138. Wilmore D W, Kehlet $\mathrm{H}$ (2001): Management of patients in fast track surgery. $\mathrm{Br}$ Med J 322: 473-476

139. Witte M B, Barbul A (2003): A Repair of full-thickness bowel injury. Crit Care Med 31: S538-S546

140. Yesilkaya $Y$, Soyhan N, Bengisu N, Sen M, Aritas $Y$ (1985): The effects of different suture techniques on collagen metabolism in experimental distal colonic anastomoses. Br J Surg 르: 987-989

141. Zantop T, Gilbert T W, Yoder M C, Badylak S F (2006): Extracellular matrix scaffolds are repopulated by bone marrow-derived cells in a mouse model of achilles tendon reconstruction. J Orthop Res 24: 1299-309 


\section{Danksagung}

Mein erster Dank gilt meinem allgemeinchirurgischen Lehrer und Doktorvater Herrn Prof. Dr. med. Hans-Fred Weiser für die freundliche Bereitstellung des Themas und die Korrektur dieser Arbeit. Ganz besonders herzlich bedanken möchte ich mich bei meinem Betreuer Dr. med. Jens Höppner für seine profunde wissenschaftliche Betreuung und Hilfe sowie menschliche Unterstützung.

Mein Dank gilt weiterhin auch allen wissenschaftlichen und technischen Mitarbeiten der Labore, in denen ich die experimentellen Arbeiten durchgeführt habe. Besonders genannt seien hier Herr Armin Andreae und seine Mitarbeiter der Stiftung Tierärztliche Hochschule Hannover. 


\section{Lebenslauf}

Am 18. August 1976 wurde ich, Vladan Crnogorac, in Berlin geboren.

In der Zeit von August 1983 bis Juni 1988 besuchte ich in Berlin zunächst die Reinhardswald Grundschule und anschließend das Leibniz-Gymnasium. Dort legte ich im Mai 1995 die Abiturprüfung ab.

Im Oktober 1995 begann ich das Medizinstudium an der Freien Universität Berlin. Im Oktober 2000 wechselte ich an die Ruprecht-Karls Universität Heidelberg und beendete das Studium mit Bestehen des 3. Staatsexamen im Juni 2002.

Seit November 2002 bin ich im Diakoniekrankenhaus Rotenburg/Wümme tätig.

Bis Mai 2004 war ich zunächst Arzt im Praktikum, anschließend Assistenzarzt in der Klinik für Plastisch-Ästhetische und Rekonstruktive Chirurgie, Handchirurgie bis Dezember 2005.

Zur Erlangung meiner Basischirurgie wechselte ich innerhalb einer hausinternen Rotation in die Klinik für Allgemein-, Viszeral-, Thorax- und Gefäßchirurgie am Diakoniekrankenhaus Rotenburg/Wümme.

Seit Juli 2007 arbeitete ich erneut als Assistenzarzt in der Klinik für PlastischÄsthetische und Rekonstruktive Chirurgie, Handchirurgie am Diakoniekrankenhaus Rotenburg und erlangte im September 2009 den „Facharzt für Plastische und Ästhetische Chirurgie" sowie im Februar 2012 die Zusatzbezeichnung "Handchirurgie“.

Seit Juni 2010 arbeitete ich an dieser Klinik in der Funktion als Oberarzt.

Im Oktober 2012 zog ich nach Berlin und arbeite dort seither als leitender Oberarzt in der Klinik für Platische, Ästhetische und Handchirurgie im Martin-LutherKrankenhaus. 